\title{
IUCN
}

Guidelines for invasive species planning and management on islands
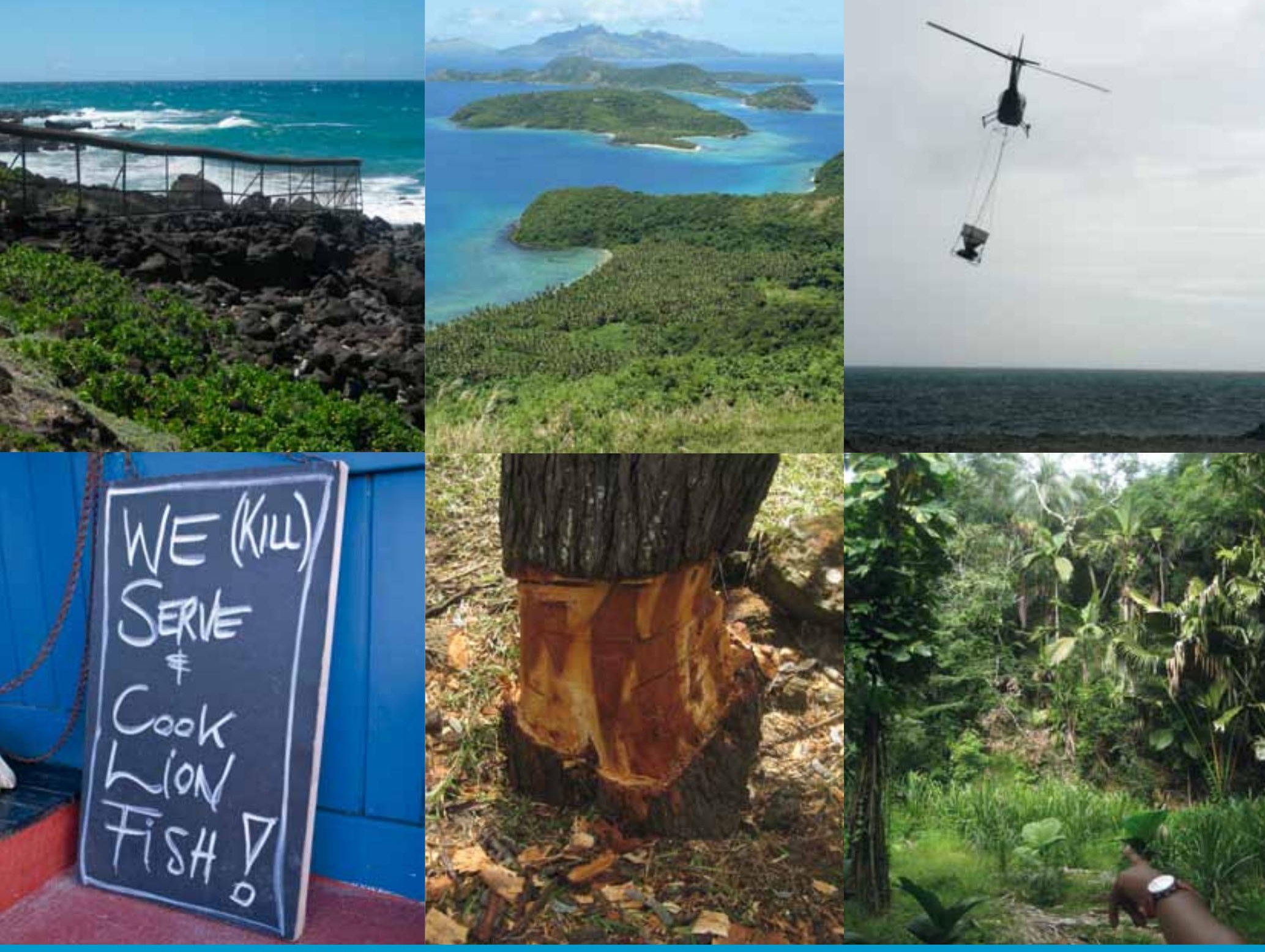

GLOBAL SPECIES PROGRAMME

SSC ISSOE CIASNEI \&





\section{Guidelines for invasive species planning and management on islands}


The designation of geographical entities in this book, and the presentation of the material, do not imply the expression of any opinion whatsoever on the part of IUCN, the European Commission, or other participating organisations concerning the legal status of any country, territory, or area, or of its authorities, or concerning the delimitation of its frontiers or boundaries.

The views expressed in this publication do not necessarily reflect those of IUCN, the European Commission, or other participating organisations.

This publication has been made possible in part by funding from the European Union under project DCI/ENV/2009/6/8 Preparation and testing of a comprehensive model for preventing and managing the spread of invasive species on island ecosystems (the Inva'Ziles Project).

Published by:

IUCN Cambridge, UK and Gland, Switzerland

Copyright:

(C) 2018 IUCN, International Union for Conservation of Nature and Natural Resources

Reproduction of this publication for educational or other non-commercial purposes is authorised without prior written permission from the copyright holder provided the source is fully acknowledged.

Reproduction of this publication for resale or other commercial purposes is prohibited without prior written permission of the copyright holder.

Citation:

IUCN (2018). Guidelines for invasive species planning and management on islands. Cambridge, UK and Gland, Switzerland: IUCN. viii + 40pp.

Compiler and editor:

ISBN:

DOI:
Alan Tye

978-2-8317-1919-1 (print version)

978-2-8317-1918-4 (PDF)

https://doi.org/10.2305/IUCN.CH.2018.15.en

Cover and interior photographs: @ Chris Buddenhagen (p. 1 centre), Sue Daly/naturepl.com (cover bottom left), Gillian Key (p. 13 centre right), Christophe Lavergne (p. 13 centre left), and Alan Tye (other photos).

All the photographs used in this publication remain the property of the original copyright holder. Photographs should not be reproduced or used in other contexts without written permission from the copyright holder.

Layout by:

Printed by:

Available from:

\section{NatureBureau www.naturebureau.co.uk}

BSR Imprimeurs SA on $115 \mathrm{gsm}$ mat paper, with cover on $240 \mathrm{gsm}$ semi-mat paper, all papers made from wood fibre from forests certified in accordance with the rules of the Forest Stewardship Council (FSC).

IUCN (International Union for Conservation of Nature)

Global Species Programme

Rue Mauverney 28

1196 Gland

Switzerland

Tel +41229990000

Fax +41229990002

www.iucn.org/resources/publications 


\section{Contents}

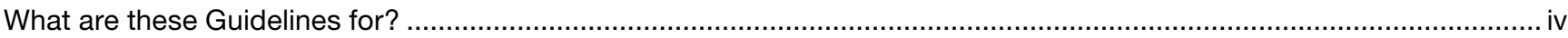

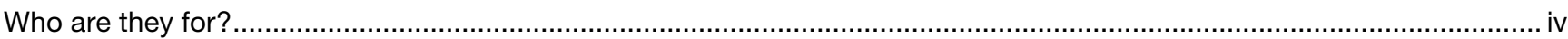

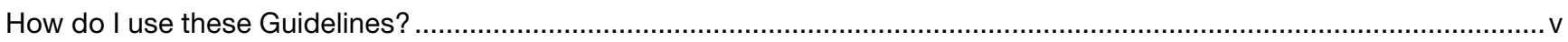

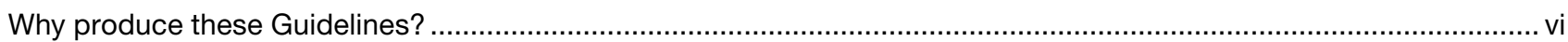

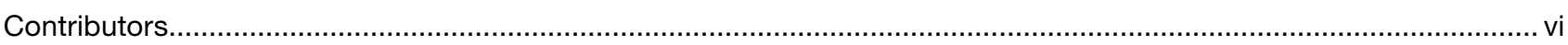

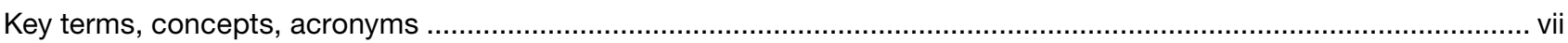

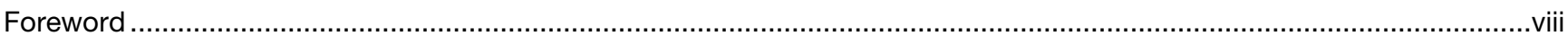

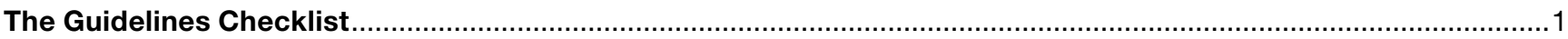

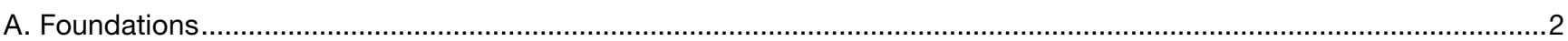

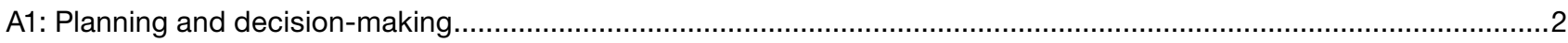

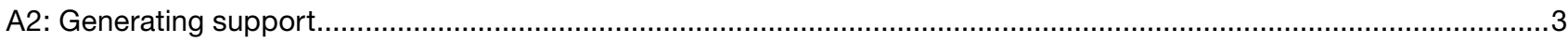

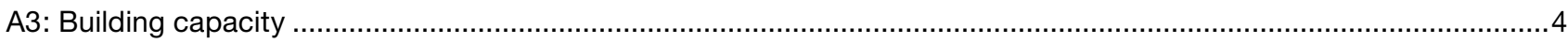

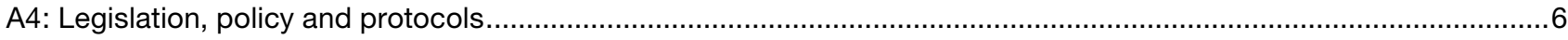

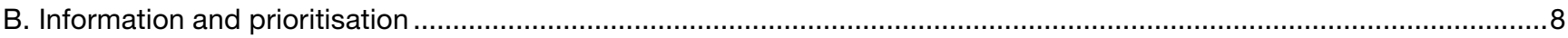

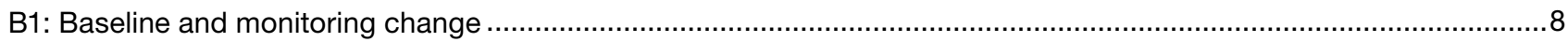

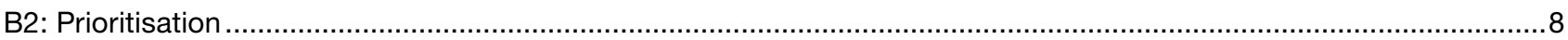

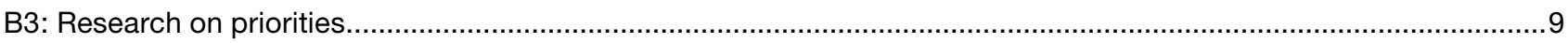

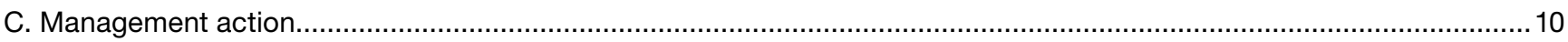

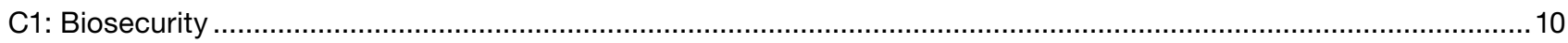

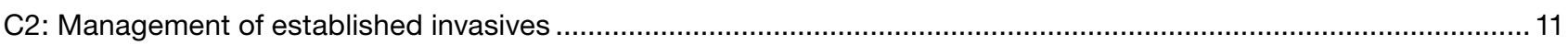

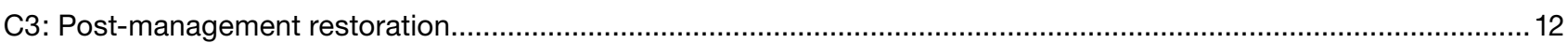

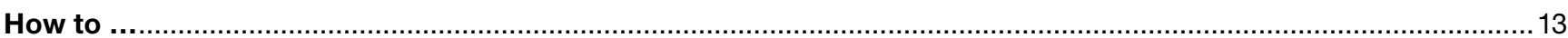

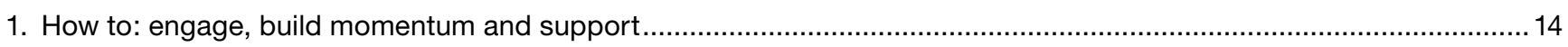

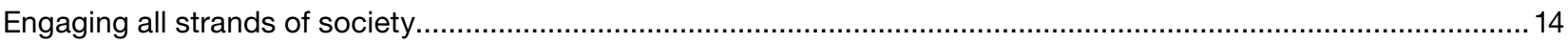

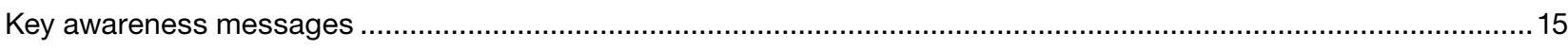

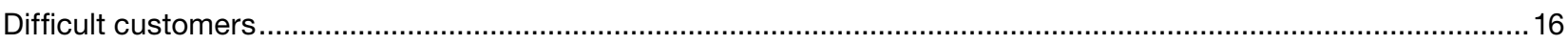

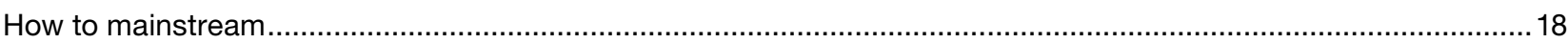

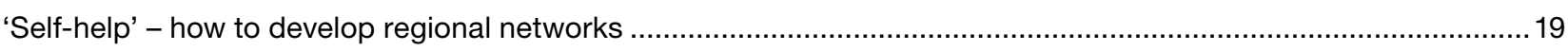

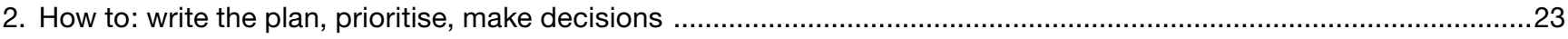

How to form and operate a National Invasive Species Committee ......................................................................23

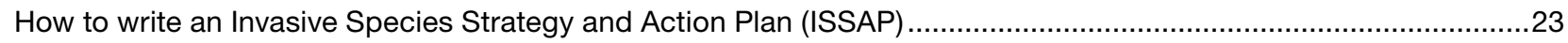

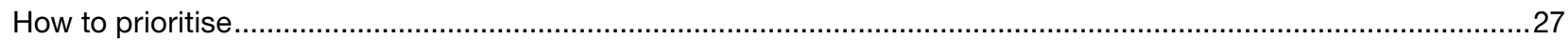

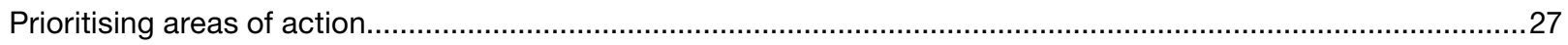

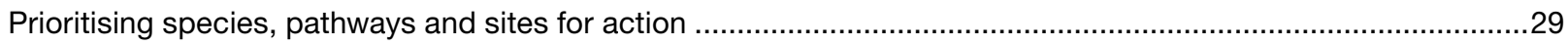

How to select management goals for a species or site .................................................................................. 31

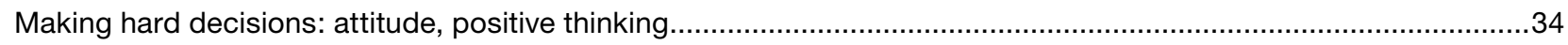

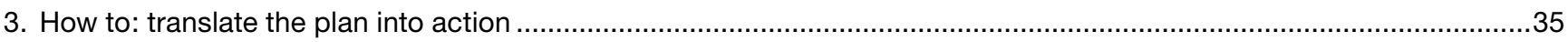

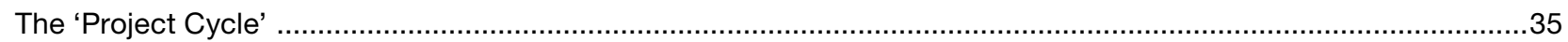

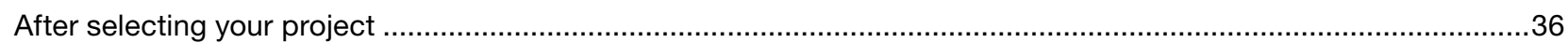




\section{What are these Guidelines for?}

The purpose of this document is to assist anyone planning and programming the management of invasive species on islands, with the aim of reducing the negative impacts of invasives on islands' rich and fragile natural heritage, communities and livelihoods.

\section{These Guidelines aim to:}

- Provide a comprehensive framework for invasive species management on islands

- Address all problem areas and facilitate prioritisation

- Increase action and improve implementation

- Increase efficiency and cooperation, reduce duplication

- Guide the work of international and regional agencies, including donors

- Guide the development of country and island programmes, including National Invasive Species Strategies and Action Plans and individual agency plans

- Guide strategic and local fundraising.

These Guidelines deal with invasive plants, animals, disease agents and other organisms, in marine, freshwater and terrestrial environments, and their impacts on the environment, biodiversity, ecosystem services, human health, economies and society. All of the main thematic areas and their objectives are required for comprehensive management of the invasive species threat. These Guidelines reflect and are compatible with relevant international conventions and standards (see Resources p. 38), and are intended to assist planners and practitioners to meet accepted standards and best practice.

\section{Who are they for?}

This document provides guidance for anyone planning an invasive species programme, on islands anywhere. It provides support for islands in developing their invasive species plans and programmes, as well as guidance for international and regional agencies in providing assistance to them (N.B. throughout this document 'regional' refers to ocean regions e.g. Pacific, Caribbean...). The guidance is intended for any organisation working on invasives on islands, including international and regional agencies, national and local government departments (e.g. quarantine, biosecurity, forestry, agriculture, water management, conservation), NGOs, protected area and conservation managers, scientists, and anyone else who has to find, plan and prioritise funds and resources for invasive species management and research.

For the purpose of these Guidelines, 'islands' are primarily islands of land in oceans, irrespective of size or isolation, but the guidance should also be useful for planning invasive species programmes anywhere, including in continental areas.

\section{If you work for an international or regional organisation, use these Guidelines to help you to:}

- Identify your niche for invasive species work in the island region(s) where you operate.

- Identify priority island needs that require action by your agency.

- Identify other agencies with whom you could or should coordinate your work.

\section{If you work for a national or local institution or programme, use these Guidelines to help you to:}

- Identify and prioritise objectives needing action within your jurisdiction.

- Design your invasive species strategy, plan your work programme, and put it into action.

- Determine how to coordinate your work with other countries and organizations, and benefit from their experience and assistance.

- Justify your projects to decision-makers and donors. 


\section{How do I use these Guidelines?}

Following this brief introduction (pp. iv-viii), the document comprises two main sections.

The first of these is a Checklist (pp. 1-12) of the essential components of a comprehensive and effective invasive species management programme, arranged in a logical order of ten Thematic Areas, grouped into three overall Themes (Foundations; Information and Prioritisation; Management Action). All 10 Thematic Areas need to be considered when planning an invasive species programme for an island or islands.

The second section, 'How to' (pp. 13-37), provides supplementary guidance on the planning and implementation process, mainly on how to engage, build momentum and support, make decisions, prioritise, and translate plans into action.

- These Guidelines may be used as an aid in planning and designing any invasive species programme, at a local, national or regional level. They help to ensure that key aspects relevant to any given situation or programme are not forgotten.

- These Guidelines are comprehensive and therefore contain many objectives, but not every country or agency needs to do everything. Not all of the objectives will be necessary for your agency or programme. Some are appropriate for implementation at a national or local level, while others require international cooperation or are more suitable for implementation by regional or international agencies. Each agency can select the objectives that it considers important for its own programme.

- The objectives are not prioritised, because priorities and needs differ in different islands, countries and territories. The Guidelines facilitate prioritisation by your country, territory, island or agency; they do not set priorities for you.

\section{Don't be dismayed - start small!}

This document might look complicated, but don't worry - if you are working on a simple plan for very limited resources it can still help you. See the 'How to' sections for common-sense advice (especially pp. 23-26), and use the Checklist to give you ideas. These Guidelines are written to help you, not to waste your time. You may feel that you have no chance to implement even just a few actions, and wonder where to start. Just focus on the following actions that islands with limited capacity can take as top priorities:

- Identify the key institutions and experts available on island, or people who can offer help from elsewhere. Work with them.

- Identify the few most important introduction pathways (e.g. garden plants, untreated wood, rat-infested freighters etc.) and work on improving biosecurity controls.

- Identify easy wins - projects where you can really achieve complete eradication or bring an invasive under effective control.

- Focus long-term management on protecting the last patches of relatively undisturbed habitat or highly threatened native species. Choose one or two projects where you can expect success.

\section{Using the Checklist}

When planning, you can use the Checklist section as a starting point and for structuring planning discussions in workshops. The Checklist outlines Actions that you may wish to include in your plan. Different islands and agencies, planning for different kinds of programme, will want to select different actions as their priorities. Also, different individual contributors to your plan may have very different ideas about what should be included in it. The Checklist should help you to select actions more objectively, balancing the suggestions made by different people and agencies. You can use the tick $\checkmark x$ boxes on the left of each Action to indicate that you have considered and either accepted $(\boldsymbol{V})$ or discarded $(\boldsymbol{X})$ it, and then refer back to the Checklist once you have your draft plan, to make sure that it includes the $\boldsymbol{V}$ Actions.

\section{Using the 'How to' sections}

You can use the decision-making tools and guidance in the 'How to' sections, to help you resolve differences of opinion and choose actions that will make a difference and which you can achieve within the limits of available (or realistically obtainable) resources.

\section{Planning from experience}

The planning process may go more smoothly if you bring in a lead facilitator experienced in this kind of planning. This is highly recommended for planning at any level, but particularly for plans serving diverse user groups, such as National (or individual island) Invasive Species Strategies and Action Plans (ISSAPs). For further guidance on how to plan, see the 'How to' sections on pp. 23-37. 


\section{Why produce these Guidelines?}

The rate of movement of plants, animals and other organisms beyond their natural range is rising sharply, due to increased transport, trade and travel. Many species that are introduced to new places by people do not cause problems in their new locations, and many bring considerable benefits to people, including in agriculture, horticulture and forestry. However, 'invasive species' (often called pests, weeds and diseases) are plants, animals, disease agents and other organisms taken beyond their natural range by people, deliberately or unintentionally, and which become destructive to the environment or human livelihoods. They threaten biodiversity, natural resources, food security, economic development, human health, and ecosystem services such as water resources, nutrient cycles and erosion. Environmental changes caused by human activities can sometimes result in a native species similarly proliferating and becoming destructive. These 'native invasive species' must also sometimes be managed.

Islands are particularly vulnerable to invasive species. Islands and their surrounding near-shore marine areas often constitute unique ecosystems, with many plant and animal species that are endemic (found only there), and which have not evolved to cope with the predators, herbivores, insect pests, highly competitive weeds, and diseases found on continents. As a result, species introduced to islands are the main cause of extinction of island native species. Islands are also susceptible to invasion because their economies rely heavily on imported goods and on travel (tourism): this generates high rates of arrival of new species, and requires strong partnerships to balance biosecurity with sustainable livelihoods.

Island ecosystems are key to the welfare and culture of 600 million islanders, one-tenth of the world's population. Invasive species on islands affect agriculture, aquaculture, fisheries, forestry and tourism; they reduce land values, damage buildings, obstruct waterways, disrupt trade and transportation, and cause or transmit diseases of humans, domestic animals and crops. Management of invasive species benefits island environments, food security, incomes, health and society, but small island states often have limited human, material and financial resources for tackling such threats.

Invasive species are an international problem, so their effective management on islands requires coordinated action by international and government agencies, NGOs, the private sector and local communities. Good resources exist to help planners and managers with many aspects of invasives management, including species control techniques, biosecurity, project design, legislation, raising awareness and many others. Some examples are listed in Resources (pp. 38-40).

In 2009, the Pacific Regional Environment Programme produced the Guidelines for Invasive Species Management in the Pacific (SPREP, 2009), a guidance document to assist Pacific islands to plan and manage their invasive species programmes, which was immediately and enthusiastically adopted throughout Oceania. In 2016, a regional consultation in the Western Indian Ocean identified planning guidance as a gap in available resources there, and a subsequent global consultation via invasives e-mail lists supported this, and showed broad agreement that the Pacific Guidelines could serve as a basis for an adapted and updated document for invasives planners on islands worldwide. Further consultations on a draft based on the Pacific Guidelines were held at the 2016 World Conservation Congress and the 2017 Island Invasives conference, and subsequently by e-mail lists. The present document is the result, and is designed to be compatible with relevant international and regional conventions, standards and indicators, to facilitate and coordinate their application, and to assist programmes and projects to meet accepted international standards and best practice. In particular, it is designed to support compliance with the Convention on Biological Diversity (Rio Convention; Article 8h: 'Prevent the introduction of, control or eradicate those alien species which threaten ecosystems, habitats or species'), the Aichi targets (especially Target 9: "invasive alien species and pathways are identified and prioritized, priority species are controlled or eradicated and measures are in place to manage pathways to prevent their introduction and establishment") and Sustainable Development Goals, National Biodiversity Strategies and Action Plans (NBSAPs) and National Invasive Species Strategies and Action Plans (see Resources p. 38).

\section{Contributors}

These Guidelines could not have been written without the voluntary contributions of many experts in invasives planning and management, and potential users on islands worldwide, who told us what kind of guidance they needed. All contributors are listed below. The Pacific Guidelines were also produced with contributions from many people, some of them the same as those who reviewed drafts of the present one. Without all of this valuable input over many years, this document would have been incomplete and unable to claim to represent islands worldwide. We hope that this broad range of contributions will foster ownership of the document by all islands, NGOs and other agencies seeking to manage invasive species throughout the world.

The Director-General of SPREP, Kosi Latu, kindly gave permission to adapt and use material from SPREP's Guidelines for Invasive Species Management in the Pacific. The present document was compiled and edited by Alan Tye, who also wrote much of the text and incorporated the contributions of 103 people (listed below) from islands and institutions worldwide. Substantial sections were written by Souad Boudjelas (Pacific), Alison Copeland (Bermuda), Geoffrey Howard (IUCN), Jill Key (Pacific, and UK Overseas Territories), Ulrike Krauss (St Lucia) and Olivier Tyack (IUCN). Piero Genovesi and Jill Key reviewed a full draft. Additional contributions, suggestions, review and encouragement were provided by Ademola Ajagbe, Katy Beaver, Alex Bond, Elsa Bonnard, Olaf Booy, Rafael Borroto, Nancy Bunbury, Earl Campbell, Dario Capizzi, Juli Caujapé-Castells, Ana Costa, Franck Courchamp, Phil Cowan, Steve Cranwell, Cathleen Cybèle, Curt Daehler, María 
Cristina Duarte, Julia Dunn, Rui Bento Elias, Marco Filipovic, Julian Fitter, Frauke Fleischer-Dogley, Jason Goldberg, Ines Gómez, Viliami Hakaumotu, Sjúrður Hammer, Chad Hanson, Olivier Hasinger, Lynley Hayes, Ben Hoffmann, Nick Holmes, Stephanie Hudin, Jason Jack, Patricia Jaramillo, Marie-May Jeremie-Muzungaile, Gabe Johnson, Chris Kaiser-Bunbury, Springer Kaye, Inti Keith, John Kelly, Michael Kiehn, Cynthia Kolar, Christoph Kueffer, Marta López Darias, Janice Lord, Ian MacDonald, Gwen Maggs, Christy Martin, Kelly Martinou, John Mauremootoo, Mathilde Meheut, Tommy Melo, JeanYves Meyer, Joel Miles, Aileen Mill, James Millett, Nitya Mohanty, Craig Morley, David Moverley, Bradley Myer, Rachel Neville, Ray Nias, Kimberley O'Connor, Warea Orapa, Shyama Pagad, Julián Pérez, John Pinel, Bruce Potter, Parmenanda Ragen, Frida Razafinaivo, Tim Riding, Gérard Rocamora, James Russell, Susana Saavedra, Adrian Schiavini, Richard Selman, Nirmal Shah, Greg Sherley, Andy Sheppard, Junko Shimura, Didier Slachmuylders, Kevin Smith, Antonio Soares, Yohann Soubeyran, Vikash Tatayah, Sophie Thomas, Anna Traveset, Magdalena Vicens, Jeanne Wagner, Josua Wainiqolo, Katherine Walls, Andrew Walsh, Marc Woodhall, Masahito Yoshida, Glyn Young and Kristi Young. Consultative meetings were organised by Olivier Hasinger, David Moverley, Ray Nias, Kevin Smith and Alan Tye. Design and layout by Barbara Creed of naturebureau.co.uk, Kevin Smith and Alan Tye.

\section{Key terms, concepts, acronyms}

Most terms, concepts and acronyms used in this document are defined at first mention in the text. The following occur frequently and are listed here for ease of reference. Some of the terms below are defined in a restricted sense for the purpose of this document, in the specific context of islands. See $<$ https://www.cbd.int/invasive/terms.shtml $>$ for a glossary of invasive species terminology.

\section{biocontrol or biological control}

biosecurity

containment

control

effective management

eradication

introduced species

invasive species

monitoring

native invasive species

native species

pathway

region, regional

surveillance
Controlling an invasive species by introducing a natural enemy, such as an insect or fungus, that specifically attacks the target species and does not attack native or economically important species.

Preventing the spread of invasive species across international or internal borders, including between islands (often termed "prevention")

Keeping an invasive species within a defined area.

Reducing the population of an invasive species.

Achieving operational success (e.g. reducing the pest to defined levels) and desired outcomes (reduced impact, recovery of impacted values) of invasive species management.

Complete elimination of an invasive species from an island (or other isolated area).

Plant, animal or other organism taken beyond its natural range by people, deliberately or unintentionally. Also termed "alien" or "non-native" species.

An introduced species that becomes destructive to the environment or human interests.

Programmes to detect change, e.g. in the distribution of invasive species, the success of management projects etc.

A native species that proliferates and becomes destructive following environmental changes caused by human activities.

A species that occurs naturally on an island or in a specified area, having either evolved there or arrived there without human intervention.

The process or mechanism by which a species is moved from its native area into a new area.

The islands in a particular ocean or part of an ocean.

Monitoring to detect new incursions of invasive species.
ISSAP

NBSAP

NGO

NISC

PILN

PIP

SPREP

WIONIS
Invasive Species Strategy and Action Plan

National Biodiversity Strategy and Action Plan

Non-governmental organisation

National Invasive Species Committee

Pacific Invasives Learning Network

Pacific Invasives Partnership

Secretariat of the Pacific Regional Environment Programme

Western Indian Ocean Network on Invasive Species 


\section{Foreword}

\section{from the President of the Republic of Palau}

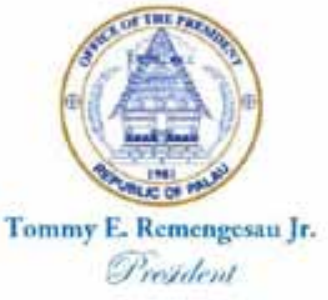

\section{Foreword}

Here in the Pacific, we like to think that we are world leaders in our commitment to the effective management of Invasive Species, and are proud of our well-documented approach to this commitment. Since 2009, our small island nations have enjoyed the use of a guidance document produced for us by the Pacific Regional Environment Programme (SPREP) known as 'Guidelines for Invasive Species Management in the Pacific', which has been adopted by all the island countries and territories of Oceania. It is therefore a special pleasure, and indeed an honor for the Pacific, to see that the International Union for Conservation of Nature (IUCN) has taken this guidance to the rest of the world by modeling their guidelines document on our original Pacific one, with the gracious permission of SPREP, while updating and expanding it with additional measures.

Our island governments have used the Pacific Guidelines as the basis for many of our national and territorial Invasive Species plans, which have, as a result, become more realistic, more objective, and more focused on the key problems that we can tackle with our limited resources. The Guidelines have also greatly helped to raise the profile of Invasive Species on our national agendas, and on the agendas of the international and regional agencies that assist us.

Given the enormity of the threat to islands posed by Invasive Species, it is very satisfying to see IUCN take these improvements to islands worldwide. We all suffer the same problems that Invasive Species bring to sustaining our livelihoods and our environments, and the solutions to these problems are similar across the planet. These new global Guidelines will assist all of us by improving our planning and management of this most severe threat to island biodiversity worldwide, and one of the greatest threats to island economies and communities.

I am very privileged to endorse this publication, which is full of practical advice and common sense, and I encourage its use by all concerned. It is a welcome addition to the set of tools available to island Invasive Species planners and managers and should result in more effective action against Invasive Species on the part of islands, island nations, and international donors. I congratulate IUCN on its foresight and concern for our island homes.

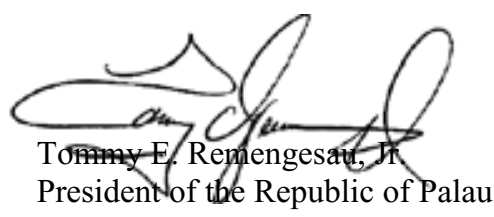




\section{The Guidelines Checklist $\square$}

This checklist sets out the essential components of a comprehensive and effective invasive species management programme, arranged in a logical order of 10 Thematic Areas within three overall Themes, listed below.

All 10 Thematic Areas need to be considered when planning an invasive species programme for an island or islands.

\section{A. Foundations}

A1. Planning and decision-making: Establish strategic, prioritised programmes for the prevention and management of invasive species, for ocean regions, island countries and territories, individual islands, and organisations.

A2. Generating support: Raise awareness of the impacts of invasive species on biodiversity, human health, livelihoods and society, and generate support, including funding, for action to manage and reduce them.

A3. Building capacity: Develop the institutions, skills, infrastructure, technical support, information management, networks and linkages required to manage invasive species effectively.

A4. Legislation, policy and protocols: Ensure that appropriate legislation, policies, regulations and procedures are in place, operating and complied with, to underpin the effective prevention and management of invasive species.

\section{B. Information and prioritisation}

B1. Baseline and monitoring change: Establish baseline information on the status and distribution of invasive species on islands, and programmes for detecting and predicting change, including range changes and emerging impacts.

B2. Prioritisation: Establish and implement effective systems for assessing risk

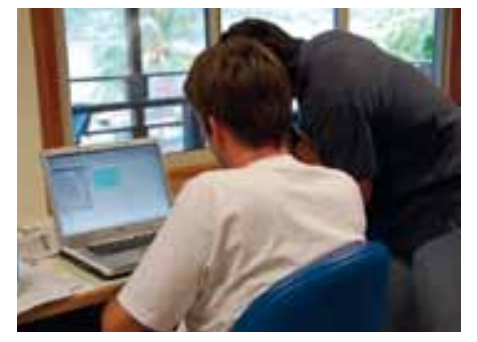
and prioritising invasive species, pathways and sites for management.

B3. Research on priorities: Understand priority invasives, including their biology and impacts, and develop effective management techniques.

\section{Management action}

C1. Biosecurity: Prevent the spread of invasive species across international or internal borders.

C2. Management of established invasives: Reduce or eliminate the impacts of established invasive species, by eradication, biological control, containment, exclusion, physical-chemical control, or impact mitigation.

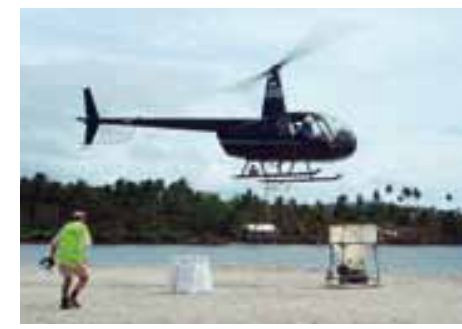

C3. Post-management restoration: Restore and maintain native biodiversity, ecosystems, ecosystem services and other values, following invasive species management. 


\section{A. Foundations}

\section{A1: Planning and decision-making}

Establish strategic, prioritised programmes for the prevention and management of invasive species,

for ocean regions, island countries and territories, individual islands, and organisations

\section{Justification}

The contents of a plan can depend heavily on who contributes to it and who argues hardest, and individual contributors may have very different ideas about what should be included. As a result, plans can end up as over-ambitious 'wish-lists', or with a highly selective focus on the interests of one particular contributing group. To deal with this, formal multi-stakeholder groups and committees help to ensure that plans take all interests into account. Formal planning guidance and decision tools can be used to make the planning process as balanced and objective as possible, and also to ensure that the plan is practical and realistic, with activities that can be completed within a specified time, at a cost that has been carefully estimated, and using funds that are either already available or can realistically be obtained in time. Invasives management is also too rarely incorporated into other land management plans, including protected area plans, and invasives workers need to engage with other sectors to overcome this.

Aim

National (or island) multi-sectoral invasive species committees in place and effectively formulating, implementing and monitoring balanced, realistic, prioritised and resourced invasive species plans and programmes for their jurisdictions. All relevant land management plans adequately incorporate invasive species management.

\section{Objectives}

A1.1 Develop regional, national and local planning mechanisms for guiding and planning invasive species action on islands

\section{Actions}

A1.1a Establish and maintain national and local invasive species committees responsible for planning and overseeing all aspects of invasive species prevention and management within their area of jurisdiction, with multi-agency representation, scientific support, and effective communication channels to senior decision-makers, all relevant sectors, and local communities (see 'How to' p. 24).

A1.1b Use regional networks and coordination mechanisms to develop cooperative initiatives, joint priorities and plans, for joint fund-raising and implementation (see A3.1, 'How to' pp. 20-33, 'Resources' p. 39).

\section{A1.2 Develop invasive} species strategies and action plans (see 'How to' pp. 23-26)

A1.2a Develop national or island invasive species strategies that complement NBSAPs, using sound planning methods and these Guidelines, in a fully consultative process including all levels from national government to local communities, and with strong scientific support.

A1.2b Develop time-specific, resource-specific national or island invasive species action plans to address the priorities identified in national strategies e.g. for particular species, pathways, vulnerable sites, ecosystems, etc.

A1.2c Incorporate economic principles into invasive species strategies and action plans, including public investment for invasive species management that yields public benefits, and apply the user-pays principle where benefits or costs are specific to certain sectors.

A1.2d Use opportunities to integrate invasives management into the plans of other sectors, plans that involve land management, plans for future change (such as climate change), and especially in protected area or threatened species management plans (see 'How to' pp. 18-19).

A1.3 Adopt, develop and use tools and aids to objective decision-making
A1.3a Use these Guidelines to guide the compilation of your invasive species strategy or plan and if possible bring in a facilitator experienced in invasives planning to help (see 'How to', pp. 23-26).

A1.3b Review existing plans and new drafts against the Checklist of these Guidelines, to identify important neglected areas for incorporation into the plan (see 'How to' pp. 27-28).

A1.3c Use the results of predictive modelling (objective B1.3 below), risk assessment, pathway analysis and similar tools (objective B2, and 'How to' section on Risk Assessment, pp. 29-31) to help decide on strategic goals, priority actions, and priority species, pathways and sites. 
A1.3d Adopt a hierarchical approach to choosing management goals (see 'How to' pp. 31-33).

A1.3e Make sure that the top priorities are fully funded before allocating resources to a lower priority (don't spread resources thinly).

\section{A2: Generating support}

Raise awareness of the impacts of invasive species on biodiversity, human health, livelihoods and society, and generate support, including funding, for action to manage and reduce them

\section{Justification}

Decision makers, the private sector and the general public often have limited understanding of the threats posed by invasive species to the environment, economies, human health and cultural values. Invasive species management competes for funding with many other interests. Lack of awareness, support and funding are key constraints limiting invasive species management on islands. Active public engagement and adequate long-term financial investment are critical to successful invasives management. Increased support and shared responsibility for invasives management are needed, including fostering individual efforts and voluntary compliance.

\section{Aim}

All strands of society, including funding agencies, decision-makers, economic and other interest groups (central government, finance, agriculture, forestry, horticulture, fisheries, aquaculture, tourism, shipping, public health, military, quarantine) and the general public, understand the risks and impacts of invasive species, and the benefits of invasive species management, for nature, the economy and human health, and all actively support invasives management. Sufficient resources are available to enable national and regional invasive species priorities to be addressed.

\section{Objectives}

A2.1: Develop programmes and materials to raise awareness of key regional, national, sectoral and community target groups (see 'How to' pp. 14-19)
A2.2: Ensure national, regional and international support (including finance) by mainstreaming invasive species issues into highlevel planning for all relevant sectors and with national and international decision-makers

\section{Actions}

A2.1a Identify priority audiences for awareness programmes, including decisionmakers, local communities and young people, especially groups involved in implementation of invasives management actions or who may influence their success.

A2.1b Collate existing knowledge about current levels of awareness, and attitudes to invasives and management methods, and carry out further surveys where necessary.

A2.1c Identify and develop priority messages and simple, convincing approaches for increasing awareness and support of different sectoral and public interest groups, including animal welfare groups.

A2.1d Provide training in developing media campaigns and also in responding to media, for invasive species workers.

A2.1e Raise pride in native species and ecosystems, and awareness of the damage to them caused by invasives.

A2.1f Disseminate messages through partners with outreach capacity or influential voices.

A2.1g Incorporate invasive species issues into existing public awareness programmes, including on related issues such as conservation and development.

A2.1h Develop and run campaigns for key messages; take advantage of events and stories that catch the attention of the public to raise interest and support.

A2.1i Incorporate invasive species into the formal education sector (primary, secondary, tertiary and adult education) through school and college curriculum development.

A2.2a Develop arguments and mechanisms to factor invasive species management into national, regional and international decision-making processes and sectoral plans for trade, transport, economic development, agriculture, fisheries, land-use planning, protected area management, and climate change.

A2.2b Use such arguments to ensure that international and national development programmes do not promote the introduction and use of invasive species.

A2.2c Demonstrate the potential economic costs of known invasive species not yet present on your islands but with high risk of introduction, and the necessity of adequately financing effective biosecurity and rapid-response plans. 
A2.2d Demonstrate the economic costs of existing invasive species problems on your islands and the economic benefits of financing action to manage them.

A2.2e Publicise successes in invasive species prevention and management, including cost-benefit analyses.

A2.2f Provide invasive species information, training workshops and resources for policy-makers.

A2.2g Ensure the inclusion of invasive species issues in high-level regional and national meetings.

A2.2h Develop mechanisms to incorporate the emergency management of new incursions of invasive species into national and regional disaster management planning and funding.

A2.3: Identify and develop external funding mechanisms for the support of invasive species management on islands.
A2.3a Develop and advertise lists of and links to potential funding sources for invasive species management and capacity development.

A2.3b Use these Guidelines and National Action Plans to identify national and shared regional priority actions, to justify funding requests to external donors, particularly for long-term strategic funding.
A2.4: Secure support for invasive species issues among local communities and the private sector (see 'How to' pp. 14-19).
A2.4a Ensure long-term local commitment and programme sustainability by promoting full participation of local communities, councils and the private sector in all aspects of invasive species management, including collection of information and sightings of invasives (citizen science), raising awareness, identifying priorities, preventing introduction and spread of invasives, and project development, management, implementation and evaluation. Provide supportive and informative feedback to the communities involved.

A2.4b Encourage and support priorities and projects that are identified by community initiatives or with full community participation.

A2.4c Develop partnerships for sponsorship from the private sector.

\section{A3: Building capacity}

\section{Justification}

The ability to manage invasive species on islands depends on competent national and regional institutions, and ready access to adequate infrastructure, equipment, skills, and accurate up-to-date information. Compared to the scale of the problem, there is a lack of basic information, trained personnel, strategic planning, infrastructure, equipment, and technical and taxonomic backup, for managing invasive species on islands. Much information on the biology, impacts and management of invasives is in unpublished local reports or even unwritten. Island invasives workers are often isolated from colleagues in other agencies, islands and countries, and don't have access to the information and skills necessary to plan and achieve management objectives. Repeated training, information services, networking and skill sharing are thus of paramount importance for the effective management of invasive species on islands.

\section{Aim}

Key agencies collaborate and have sufficient, adequately trained staff. Communities have the capacity to participate fully in invasive species management. Good infrastructure and equipment for biosecurity and management are available, and competent identification services are linked effectively to those who need them. Information on invasive species biology, impacts and management is readily available to all, so there is a strong scientific basis for decision-making, resource allocation, prediction of impacts of introduced species, and management. All this enables efficient and effective management of invasive species.

\section{Objectives}

A3.1 Establish and strengthen mechanisms that facilitate communication, information sharing and cooperation between invasive species

\section{Actions}

A3.1a Support, strengthen, advertise and join global and regional invasive species networks, exchanges and skill-sharing mechanisms, such as email distribution lists, and use them to share species lists, management experience and other information, and to make requests for assistance (see 'Resources' p. 39). 
workers, including networks of expertise, information, workshops and exchanges between islands, institutions and other sources of technical and scientific assistance.

A3.1b Cooperate to establish, maintain, strengthen and promote regional coordination and cooperation initiatives for invasive species management, such as the Pacific Invasives Partnership (PIP), the Regional Invasive Species Councils of Melanesia and Micronesia, and the IUCN French Committee initiative on invasive species in the French overseas territories.

A3.1c Use regional cooperation mechanisms to develop shared regional priorities and collaborative Action Plans, and cooperate to monitor and evaluate them.

A3.1d Promote cross-sectoral exchange of experience and understanding by involving scientists, environmental managers and local citizens as fully as possible in invasive species projects.

A3.1e Cooperate to establish and maintain global mechanisms for coordination and collaboration between regional networks and agencies.

A3.2: Develop, maintain and publicise competent regional and national sources of taxonomic, scientific and technical support for invasive species management on islands in all ocean regions.

A3.2a Cooperate to review and strengthen invasives management capacity in relevant regional agencies (some listed in Resources p. 39).

A3.2b Develop and strengthen links to sources of technical advice and assistance, including regional registers of invasive species management agencies, experts and their expertise, within and between ocean regions and elsewhere.

A3.2c Cooperate to establish and maintain regional resource centres for essential invasive species services (such as for biocontrol, risk analysis, information management etc.).

A3.2d Develop and strengthen links to taxonomic institutions, experts, networks, online identification services, and national and regional species reference collections (herbaria etc.), within and between ocean regions and elsewhere.

A3.3: Strengthen and maintain competent national and local institutions and staffing, to coordinate, manage and implement invasive species programmes and to promote full participation in invasive species management by local communities and citizens.
A3.3a Improve cooperation between national and local institutions responsible for different aspects of invasive species prevention and management, such as through invasive species committees with government endorsement (see A1.1a).

A3.3b Regularly review national staffing capacity at all levels, and strengthen weak areas, ensuring that key skill areas, responsibilities and resources are represented in or available to the main invasive species management agencies. Key skill areas roughly correspond to the themes of these Guidelines and include: policy and planning, facilitation for community involvement, communication to decision-makers, fundraising, legal, scientific, technical (prevention and management), monitoring and evaluation. See A2.2 for raising support to strengthen capacity.
A3.4: Promote and develop training programmes to cover all aspects of the invasive species, from planning, policy and fundraising to practical management and dissemination of lessons learnt. management, data

A3.4a Review recent and current training programmes and identify important gaps and target groups.

A3.4b Design and implement cooperative invasive species training plans, incorporating repeat training at intervals that reflect staff turnover rates, post-training capacity development mechanisms, and cross-sectoral training (e.g. biosecurity staff with customs, agriculture staff with conservation etc.).

A3.4C Use a range of training methods and content appropriate for different target groups, including formal courses, exchanges, participation in demonstration projects, etc, and including training for local communities involved in invasive species monitoring and management.

A3.5a Review existing regional and national invasive species management infrastructure and facilities, and produce long-term development plans.

A3.5: Develop or upgrade regional and national infrastructure and facilities for invasive species management.
A3.5b Establish or strengthen essential regional and national facilities such as inspection and quarantine stations and rapid response centres.

A3.5c Cooperate to develop regional and international institutions that provide facilities and resources unavailable within individual countries, such as biocontrol or rapid-response facilities, helicopter services etc, and establish strong links to users. 
A3.6: Develop, update, publicise, make accessible and utilise global, regional and local internet-based and other information resources on invasive species and their management.
A3.6a Establish and maintain national and regional databases of invasive species projects, including technical information, objectives, results, outcomes and lessons learnt.

A3.6b Cooperate to develop, maintain and advertise global and regional information resources and services on invasive species and best practices (management techniques, pesticide information, biocontrol agents and other techniques, monitoring and data management protocols), as repositories of information useful for islands (some good examples are listed in Resources p. 39-40).

A3.6c Encourage and provide input of island information to global and regional information resources.

A3.6d Develop national and local information resources on invasive species, to compile and publicise local knowledge and management information, and to raise public and political awareness and support.

\section{A4: Legislation, policy and protocols}

Ensure that appropriate legislation, policies, regulations and procedures are in place, operating and complied with, to underpin the effective prevention and management of invasive species

\section{Justification}

Invasive species have economic, environmental and societal impacts, so their management can involve many different agencies working to different pieces of legislation and procedures. Responsibilities and laws are often unclear, inadequate or incompatible. Where laws and regulations exist, compliance and enforcement are often inadequate. Effective, consistent legislation, agreed protocols, general compliance and effective enforcement are vital for coordinated, effective action.

\section{Aim}

Islands collaborate to develop and work within consistent legislative frameworks, aligned with regional and international instruments. Protocols are mutually agreed and sufficiently similar that all those involved in the management of invasive species achieve efficient and effective cooperation. Legislation and regulations are widely understood, generally complied with, enforced and supported by the judiciary.

\section{Objectives}

A4.1: Develop, promote and adopt an effective policy, legal and enforcement framework for invasive species management on islands.

\section{$\checkmark$ Actions}

A4.1a Develop, disseminate and adopt practical policy and legislative guidelines covering all activities that affect invasive species management, including biosecurity, trade, transport, construction, military activities, disaster response, development assistance, research, agriculture, aquaculture, forestry, horticulture, pet ownership, tourism, surveillance, risk analysis, biocontrol, eradication, declaration of noxious pests etc., using best principles and international standards (see 'Resources' p. 39).

A4.1b Develop partnerships with law schools and legal departments to ensure that invasive species are adequately included in environmental and other legislation.

A4.1c Review environmental, fisheries, agriculture, aquaculture, forestry, horticulture and biosecurity and other pertinent legislation in each island jurisdiction to determine their adequacy for protecting biodiversity, economies and health against invasive species, and to identify gaps, inconsistencies and conflicts.

A4.1d Develop a unified national and regional inter-agency approach to invasive species policy, legislation and management.

A4.1e Ensure that the legal framework comprehensively covers border control, rapid response, prohibition of movement and ownership of invasives, requirements for control of invasives, and access to private and public lands for management.

A4.1f Establish a legal framework that permits and promotes strict invasive species prevention and management on islands administered by continental countries, and explicitly governs and controls inter-island movement within island countries.

A4.1g Ensure full participation by all stakeholders, including technical staff and local communities, in the development and implementation of legislation.

A4.1h Incorporate economic principles into national legislation for addressing invasive species including appropriate taxes, the polluter-pays and user-pays principles, and public investment when invasive species management yields public benefits. 
A4.1i Develop and invest in mechanisms to improve compliance with and enforcement of invasive species legislation, and successful prosecution of infractions.

A4.2: Develop and promote effective, standardised regulations and protocols for invasive species management on islands, derived from consistent policies and legislation, aligned with applicable international requirements, and based on sound scientific information and management principles.
A4.2a Develop model technical protocols and procedures for islands, establishing best practice for commonly used processes, procedures and management objectives (refer to Thematic Areas C1-C3 below).

A4.2b Periodically review national and regional policies and procedures on biosecurity, risk assessment, trade, movement, holding, release into the environment, establishment and management of invasive species, revise to bring up to international standards and best practice, and harmonise across ocean regions.
A4.3: Ensure full participation of island states in the development of international standards, conventions and programmes relating to invasive species, including movement in commerce, to ensure that they reflect the needs of islands.
A4.3a Promote and expand membership of and contributions to international conventions, committees and working groups by island countries and agencies.

A4.3b Ensure that national and regional contributions to international policymaking are consistent and based on full consultation between all concerned sectors. 


\section{B. Information and prioritisation}

\section{B1: Baseline and monitoring change ${ }^{1}$ \\ Establish baseline information on the status and distribution of invasive species on islands, and programmes for detecting and predicting change, including range changes and emerging impacts}

\section{Justification}

Lack of information on the status of invasive and potentially invasive species on islands, including their inshore waters and reefs, hampers their management. Information on the distribution, abundance, dispersal mechanisms and impacts of invasives, as well as information on the abundance and distribution of native biodiversity, is essential for prioritising species and sites for management, for planning effective management projects, for evaluating their success, and as a basis for monitoring the movement and changing impacts of invasives. Monitoring is also essential for detecting or predicting trends and emerging threats such as effects of climate change on invasive species.

\section{Aim}

Knowledge of the current status of invasive and potentially invasive species and of native biodiversity on islands, including their inshore waters and reefs, is adequate and readily available, facilitating prioritisation, planning, effective management, and monitoring change. Effective systems are in place for monitoring the movement of introduced species within and between countries and islands, for detecting trends, predicting change, and evaluating management outcomes.

\section{Objectives}

B1.1: Baseline. Generate, update and make available baseline information and checklists of terrestrial and aquatic introduced and native species, introduction pathways and sensitive sites for all islands and island states.

\section{Actions}

B1.1a Compile island checklists, GIS databases and other information resources on native and introduced species, susceptible sites (i.e. sites with high exposure to invasives, such as ports, gardens, road verges) and sensitive sites (i.e. sites that might suffer high impact from invasives, such as protected areas and aquatic systems).

B1.1b Identify and document the pathways and vectors of introduction of invasive and potentially invasive species (see 'How to' p. 29-30 and 'Resources' pp. 39-40).

B1.1c Periodically review species and site inventories, identify gaps (ecosystems, islands or taxonomic groups) and plan priority surveys.

B1.1d Carry out priority surveys and update information resources.

B1.1e Publish and share species lists and other information locally and with other islands, including online and in the databases listed in Resources (p. 39).

B1.2a Promote, improve and adopt best-practice techniques for monitoring the spread of introduced species within islands, sensitive natural areas and other high-risk sites.

B1.2b Draw up and implement monitoring plans for species and sites identified as priorities (by prioritisation methods described in objective B2 below) on each island.

\section{B1.2: Monitoring local} spread $^{2}$. Implement effective standardised techniques for monitoring the spread of introduced species within islands.

B1.3: Prediction. Model the future pattern of invasions, including the effects of major environmental and societal changes such as climate change, forest loss and changing wealth patterns.
B1.3a Enlist, use and cooperate with global and regional expert resources to model the future pattern of introductions and invasions on islands ('horizon scanning') to identify high-risk potential invasives and their introduction pathways, based on the presence of invasive species in nearby islands or key trading partner countries, and on actual or likely economic, societal or environmental trends.

B1.3b Use the results of predictive modelling to select overall strategic planning goals (see A1.3).

\section{B2: Prioritisation}

Establish and implement effective systems for assessing risk and prioritising invasive species, pathways and sites for management

\section{Justification}

Most islands contain large and increasing numbers of species introduced from other places by people, either deliberately or accidentally. Some of these are valuable (medicinal plants, crops, ornamentals etc.) while some have serious impacts.

1 Monitoring and evaluation of management action are covered under Objectives C2.2 and C3.1 below.

2 Monitoring inter-island movement of invasive species (at ports and other entry points) equates to biosecurity surveillance, and is covered under Objective C1.4 below. 
Often the largest group is of species that are not yet causing problems on a given island but which may become invasive in the future, including recently introduced species, plants in gardens, and pets. Risk analysis, including weed and pest risk assessment and pathway analysis, has three main functions: to determine whether to permit or refuse the introduction of a new species into a country or island; to determine the importance of pathways for the introduction of known pests; and to determine which species, among the total of introduced species already present on an island, may become serious future problems. Management on different islands or sites may also need to be prioritised according to their biodiversity or other values. Objective assessment systems are available to aid making such decisions but are under-used.

\section{Aim}

Planners and managers use effective decision tools to determine objectively invasive species risks and prioritise the management of species, pathways, islands and sites. Resources are dedicated to managing the species causing the most damage, the species and pathways posing the greatest risks, and the sites most at risk and where action is likely to be most effective and practicable.

\section{Objectives}

B2.1: Design, develop and adopt simple and effective risk assessment and prioritisation systems for use on islands.

\section{Actions}

B2.1a Use pathway analysis to identify the pathways of introduction of non-native species and use the results to prioritise the pathways for management.

B2.1b Adopt or adapt model systems for assessing the risk of species becoming invasive, and apply them to (i) decision-making for import and border control; and (ii) determining the likelihood of established introduced species becoming invasive.

B2.1c Use risk assessment for border control, to decide which species should be allowed to be imported to an island or country.

B2.1d Use risk assessment to assess all the introduced species already present on an island, taking into account global information on the species and local information on its behaviour on-island, and use the results to prioritise species for management.

B2.1e Use and adapt island- or site-prioritisation tools based on biodiversity and other values (e.g. the Threatened Island Biodiversity database: see 'Resources' p. 39), to prioritise action on different islands or sites.

\section{B3: Research on priorities}

Prioritisation identifies species, sites and introduction pathways for immediate management action. It may also identify potential priorities for which further research is needed to confirm their importance, such as research on possible impacts. Effective management requires understanding the target species' ecology, population dynamics and dispersal mechanisms, which may need further research, while effective techniques for managing a species or pathway may not exist and will then need to be developed. Priority-focused research is needed to provide the knowledge required for effective management, while research on ecology and impacts of introduced species feeds back into prioritisation.

\section{Aim}

Research programmes are focused on providing the information needed for effective management, and for well-informed risk assessment and prioritisation.

\section{Objective}

B3.1: Carry out research on the impacts, ecology, biology, introduction pathways and management of high priority invasive species and poorly known introduced species.

\section{Actions}

B3.1a Develop regional and national invasive species research plans based on objective prioritisation.

B3.1b Investigate the ecology, biology, population dynamics and introduction pathways of priority invasive species.

B3.1c Investigate the ecology and the current and potential impacts of introduced species whose impacts are unconfirmed but suspected to be serious.

B3.1d Review available management techniques for priority invasive species, test existing techniques and develop new ones where necessary for effective management.

B3.1e Develop innovative control methods, such as genetic pest management (GPM) techniques, to improve management effectiveness (Harvey, et al., 2017). 


\section{Justification}

Preventing the passage of species across borders, especially across the natural boundaries between islands isolated by ocean, is the most cost-effective way of managing the threat they pose: costs per species are lower for prevention than for management of established invasives (see 'How to' pp. 31-33). Prevention also avoids impacts of a species whereas management after establishment often takes place only after impacts have occurred. Prevention works by identifying introduction pathways and establishing four barriers: 1) Pre-export control aims to prevent the export of known invasives from places where they are established, to islands; 2) Pre-border control regulates importation to an island or country; 3) At-border control aims to prevent the arrival of species on-island; 4) Post-border early detection and rapid response (EDRR) aims to detect and eradicate completely newly-arrived species before they spread far beyond the point of arrival, because treatment is cheaper and easier then. An effective biosecurity system must include all four elements. Prevention systems must also aim to be comprehensive, not focusing uniquely on agricultural pests.

\section{Aim}

Effective systems are in place on islands throughout the world to regulate intentional introductions and to detect and manage unauthorised or accidental introductions across international borders and between islands.

\section{Objectives}

\section{C1.1: Pre-export control.}

Develop and implement improved inspection, treatment, packing and transportation procedures and methods, for transport and commodities leaving countries and islands where priority invasive species are present.

\section{$\checkmark$ Actions}

C1.1a Promote the development and adoption of stronger international standards governing the control of potentially invasive species at export.

C1.1b Use risk and pathway analysis (section B2 above) to identify priority invasive species that threaten your islands owing to their presence in trading partners and sources of transport coming to your islands, and to identify the pathways by which they may arrive.

C1.1c Review pre-export inspection and treatment procedures for controlling priority pathways and preventing the export of priority invasive species, particularly in the main trading partners of your islands and on infested islands that supply relatively pristine islands, and identify gaps in coverage.

C1.1d Strengthen, develop and implement adequate pre-export controls directed at preventing the export of priority invasive species

\section{C1.2: Pre-border control.}

Apply a rigorous process of risk analysis (Sections B1.3 and B2 above) to permit or prohibit the deliberate introduction of species and the movement of potential carrier goods between countries and between islands within a country, and implement controls on transport vessels while in transit to islands, to prevent accidental introductions.

C1.2a Establish and implement national and internal (inter-island) risk assessment and pathway analysis (Sections B1.3 and B2 above) for proposed deliberate movements of species and for the movement of goods that may accidentally carry invasive species.

C1.2b Facilitate a common global precautionary approach to decision-making on proposed introductions, as far as possible based on positive lists (sometimes called 'white lists') with species categorised as (1) low-risk 'permitted' species, (2) moderate-risk 'restricted' species, and (3) high-risk 'prohibited' species, and the automatic prohibition of any organism or commodity not included on the permitted or restricted lists.

C1.2c Cooperate to promote, apply and enforce international and national mechanisms for the treatment of goods and transport vessels while in transit, such as the international ballast water management convention (BWMC), hull-fouling treatment protocols, pest control on vessels, and insecticidal treatment on aircraft.

\section{C1.3: At-border control}

Establish and maintain effective quarantine, transport and border control systems at national borders and between islands within countries.
C1.3a Review existing border controls, transport controls and quarantine systems to identify gaps in the control of priority pathways, vectors (ships, planes, people, carrier organisms, carrier goods etc) or taxa (i.e. all invasives, not just agricultural pests), and technical or resource constraints on quarantine implementation.

C1.3b Make citizens and visitors aware of invasive species threats and biosecurity regulations, using signs, leaflets or videos on airlines, inter-island ferries and at entry points. Provide disposal containers for prohibited items. 
C1.3c Develop and strengthen terrestrial, freshwater and marine quarantine control systems at border and island entry points, ensuring that border control is carried out by appropriate agencies with officers trained broadly (not just in agriculture) to recognise invasive species and their pathways, with powers to intercept, confiscate and decommission, with adequate detection, storage and disposal facilities, and with comprehensive data collection and management.

\section{C1.4: Post-border early} detection and rapid response (EDRR). Establish and maintain effective systems to detect incursions of invasive species reliably and quickly, and mount rapid eradication responses.
C1.4a Develop regional information centres for monitoring the spread of introduced species and make available status and distribution updates from individual islands.

C1.4b Review existing port and border surveillance and rapid response arrangements and identify national, island, pathway or taxonomic gaps, particularly high-risk species and pathways identified by risk assessment (Section B2 above).

C1.4c Design and implement surveillance systems at island entry points and introduction sites (nurseries, experimental farms etc) using best-practice techniques, including specific surveillance plans and identification materials for high-risk species and pathways, and specific reporting protocols when organisms are detected.

C1.4d Develop citizen science monitoring and reporting programmes for general 'unknowns' and for specific pests, such as bee-keeper networks for Hymenoptera.

C1.4e Develop and put in place rapid response plans with staff trained, dedicated funding and equipment ready for use, for dealing with different kinds of newly arrived pest and with the emphasis on fast eradication. Test the plans by field trials.

\section{C2: Management of established invasives}

Reduce or eliminate the impacts of established invasive species, by eradication, biological control, containment or exclusion, long-term physical or chemical control, or impact mitigation

\section{Justification}

Management of the invasive species that are established on islands suffers from a lack of resources relative to the size of the problem, and resources are often devoted to long-term control, whereas a large initial investment in eradication or biological control might produce a more cost-effective result in the long term. The results of management projects are often inadequately recorded, so project cost-effectiveness cannot be judged, and results are often not publicised, limiting the ability to learn from the experience of others.

\section{Aim}

To ensure long-term cost-effectiveness, a hierarchical approach to choice of management goal is adopted (see 'How to select management goals' pp. 31-33). To ensure value for money, all management projects monitor operational effectiveness (success in achieving control) and outcomes (success in protecting biodiversity or other values). Results are disseminated to permit improvement in management practices. Impacts of established invasive species are reduced or eliminated by means of effective eradication, biocontrol, containment, exclusion, chemical-physical population control, or impact mitigation.

\section{Objectives}

C2.1: Design, adopt and use decision tools to assist in the choice of management goal and management techniques, to ensure costeffectiveness and the efficient use of limited resources.

C2.2: Design and implement effective management programmes appropriate for each species and site, incorporating best-practice standards (see 'Resources' p. 40).

\section{Actions}

C2.1a Design, adopt and use decision tools that assess the feasibility and costs of different management options, to assist in the choice of management goal (see 'How to select management goals' pp. 31-33, Cacho and Pheloung, 2007; IPMDAT: see Resources p. 40) and the techniques used to reach that goal. 
C2.2c Design and implement eradication projects for species where eradication is judged feasible with accessible resources (see 'How to' pp. 31-33, 'Resources' p. 40), particularly for new arrivals, or on small islands, and including multi-species eradication for increased effectiveness and prevention of invader release effects.

C2.2d Design and implement biological control projects for appropriate species, especially widely distributed species that are difficult to manage by other means.

C2.2e Design and implement control by genetic management techniques such as sterile male, transgene incorporation etc., where considered feasible, compliant with international standards and socially acceptable (see Harvey, et al., 2017).

C2.2f Design and implement containment projects for species in appropriate situations, such as recent arrivals, or valued crop plants that are also invasive.

C2.2g Design and implement exclusion projects for appropriate situations, including the exclusion of selected invasive species from sites of exceptional conservation value using 'mainland island' techniques.

C2.2h Design and implement effective physical or chemical control projects for appropriate situations, especially high-value sites invaded by a variety of introduced species ('site-led' management).

C2.2i Where impacts are caused by an invasive species that is not susceptible to effective direct control, design and implement impact mitigation measures, including the protection of high-value biodiversity by means such as nest protection or ex situ population maintenance.

\section{C3: Post-management restoration}

Restore and maintain native biodiversity, ecosystems, ecosystem services and other values, following invasive species management

\section{Justification}

Sometimes, control of an invasive species is followed by rapid and adequate recovery of the native ecosystem or of the economic or societal value affected by the target species. But in other cases, native species may fail to recover or unforeseen adverse consequences may occur, such as invasion by other introduced species. In such cases further intervention may be required to assist the recovery of native biodiversity or other values. This may include specific restoration projects for individual native species, or management of other invasive species.

Aim

Native species, ecosystems, ecosystem services and other impacted values recover to planned levels following invasive species management.

\section{Objective}

C3.1: Design and implement post-management restoration projects to ensure that invasive species management projects achieve their ultimate goal, be it recovery of native species and ecosystems, ecosystem services, or other economic or societal value.

\section{Actions}

C3.1a Ensure that all invasive species management programmes are accompanied and followed by long-term monitoring and evaluation of outcomes, including the expected recovery of native species, ecosystems and other impacted values.

C3.1b Ensure that measures are taken to limit further pressures on the native biodiversity, ecosystem or other values, including biosecurity to prevent further invasions.

C3.1c Where invasive species management is found to be followed by other invasions, design and implement follow-up invasive species management projects, as required.

C3.1d Where further intervention is identified as necessary to achieve full recovery of biodiversity or other values following invasive species management, design and implement projects to restore key species (including threatened species), habitats or landscape features, as required. 


\section{How to ...}

1. ... engage, build momentum and support
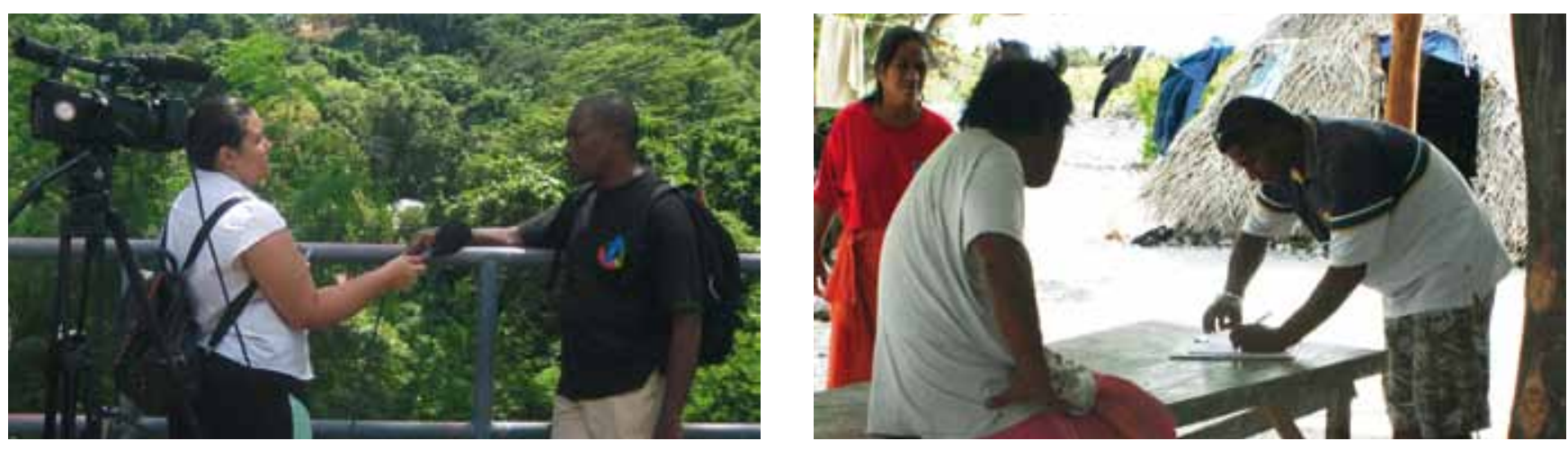

2. ... write the plan, prioritise and make decisions
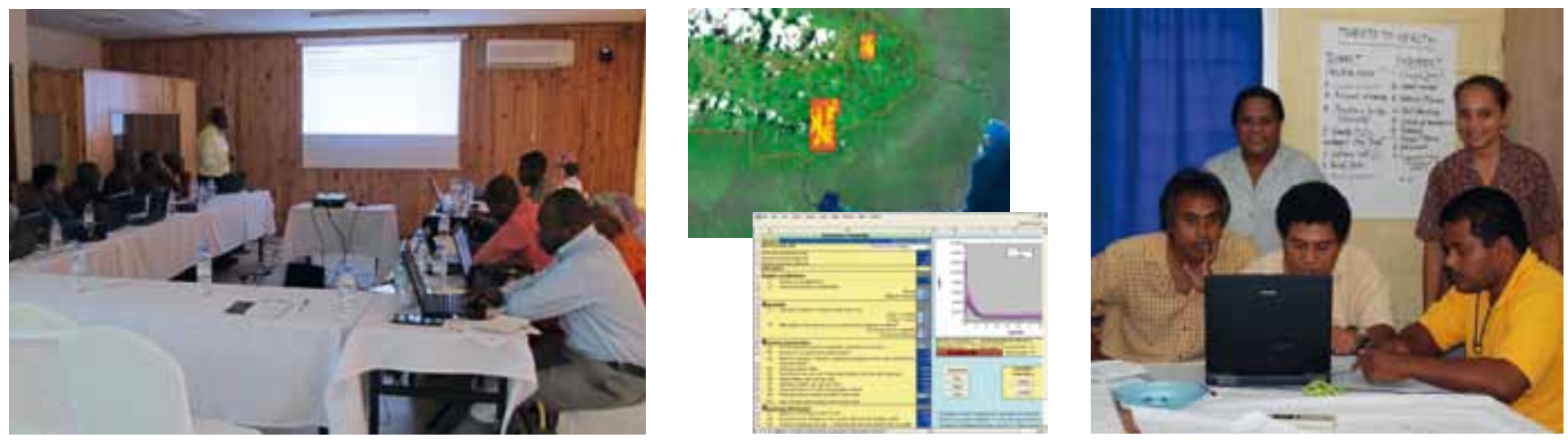

3. ... translate the plan into action
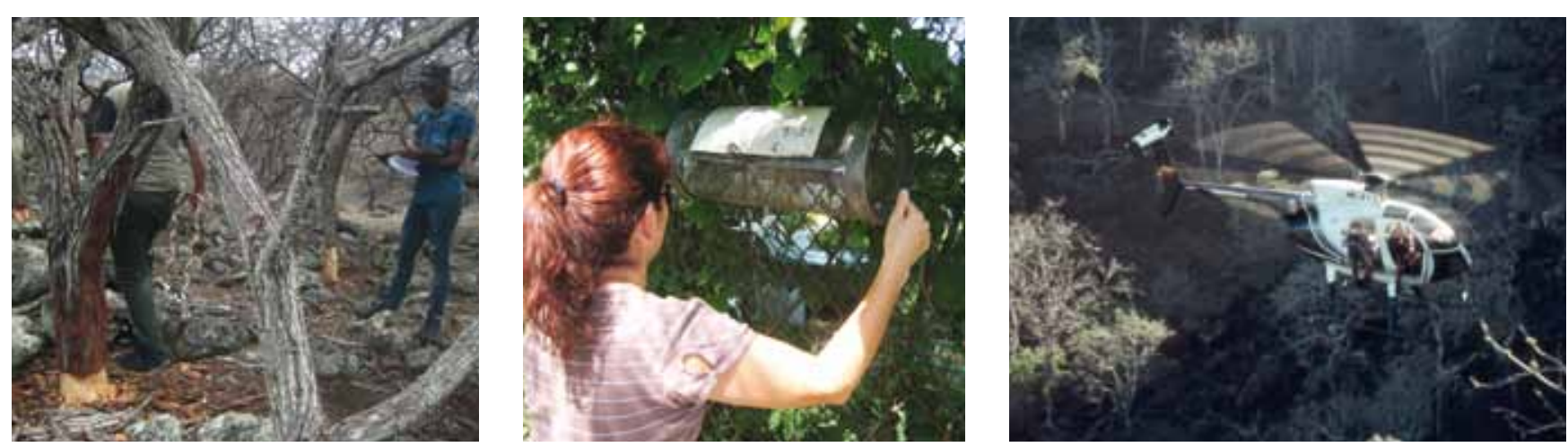


\section{How to: engage, build momentum and support}

\section{Engaging all strands of society}

It is impossible for island governments to take responsibility for all of the activities required to prevent and manage invasive species; they need the aid and understanding of the public. Ideally, governments, NGOs, the private sector and the general public should share the tasks of preventing and managing invasive species. Island governments usually do not have enough technical capacity and resources, and often are not fully aware of the damage done to livelihoods and development by invasive species. Increasing public and political awareness of the problems caused by invasive species is needed in order to generate support for action against them.

A communication strategy can help. Focus on educating people to appreciate the damage from invasives and what they can do to tackle them. Publicity and persuasion need to be directed at decision-makers, local communities, NGOs and businesses, and children too (building future social consciousness). You are trying to change their behaviour, and the arguments used for each target audience might be very different: for example, a strong argument with decision-makers and donors may be that invasive species management increases ecosystem resilience to climate change, whereas farmers will respond best to information about invaders that may soon impact their farms. The communication tools used (e.g. posters, newsletters, articles in the local press, radio and TV interviews, web sites, blogs, social media...) will also differ for different target audiences; e.g. use the radio and TV for local communities who don't read much or use the internet. Remember that media people usually need support to ensure that they get details correct and explained accurately in plain language.

Try to motivate and cultivate environmental stewardship: media such as posters, websites and TV spots can include a section on 'what you can do to help tackle this menace' or 'my role in fighting this invader'. Encourage people to report sightings, not to spread invasive plants when farming or gardening, and undertake management in their local areas. Awareness of the risks and costs of invasive species, and the best ways to manage them, can quickly bring local communities, NGOs and businesses into invasives decision-making, prevention and management. Where local interest and support have begun, adults and schoolchildren can be involved in 'citizen science' for the collection of information, such as detecting new invasions and complementing monitoring done by technical agencies. Smartphone apps working with a digital camera and perhaps a GPS too, can allow images of species to be uploaded and identified quickly (e.g. PlantNet: see 'Resources' p. 39). An example of citizen involvement is the Naturewatch initiative on the iNaturalist web site in New Zealand (<http://inaturalist.nz/>). Citizens can sign up and report on an online form any species they don't recognise. Such initiatives can be effective, and involvement can be very pleasing to members of the public, especially if they see the results of their own efforts, and their names in the media.

Where awareness is greatest, communities will carry out some aspects of invasive species prevention and management themselves. Many islands have community groups that manage actions like recycling and beach cleaning, and with increased awareness of invasive species issues, such groups can take charge of invasives management too.

On the next two pages are some crucial points to bear in mind when speaking to or writing for the general public and media about invasive species issues. 


\section{Use plain language! (Remember: to most people, aliens are from outer space...)}

As someone who works with invasive species every day, you are used to using the technical jargon. But when speaking to or writing for a general audience, whether it be a local community group, an individual landowner, a meeting with government officials, or an interview or article for the media, don't use those technical terms unless you are prepared to explain every one, more than once, and you are prepared to be still misunderstood (no matter how much you explain jargon, people will still misinterpret it). In public awareness materials and campaigns, and especially in stakeholder consultations, avoid using technical words, like 'alien', 'exotic', 'invasive', 'biodiversity', which may be very familiar to you as an invasives worker, but which most ordinary people do not really understand. Put yourself in their place: to most people the word 'alien' only means beings from outer space, and 'exotic' conjures up something desirable. In ordinary speech the word 'invasive' is not associated with particular impacts in the same way that common terms like 'pest' are. So use plain language: say 'harmful', 'pest' or 'weed' instead of invasive, say 'introduced' or 'not native' instead of alien or exotic, and say 'nature', 'wildlife' or 'our own native species' (according to the context) instead of biodiversity. Awareness materials that help people to learn technical terms may be useful, but always start with the assumption that people do not know them, so use their language.

\section{Which species are introduced and which native? (Most people don't know!)}

Managing invasives and monitoring introduced species are hampered by most people having little idea about which species are native and which are introduced. On most islands people (including their politicians) are simply not aware that the 'forests' and gardens around them are mostly made up of introduced and invasive species. As a consequence, people do not value their native plants and animals, and don't realise what damage the invaders are doing. Islands need lists of native, introduced and invasive species (of all taxonomic groups) and publicity materials to help people recognise them and deal with them appropriately. Materials and campaigns can be based around common invasives that people recognise but do not realise are introduced, and also around the value (cultural, economic) of genuinely native species. You can then encourage people to avoid using invasives wherever possible (as garden plants, for example) and use native species instead.

\section{What are the impacts of invasives, and what benefits come from managing them? (Apart from farmers, most people have only a vague idea...)}

Focus on the invasives whose impacts affect people most. Most people will not care about invasive species that also bring them benefits. Show how managing the damaging ones could reduce their impacts, and use well-known pest disasters to promote biosecurity - stopping pests coming into the island will prevent more such disasters in future. Use success stories: show how a difference can be made through successful eradication, biocontrol and other techniques. Try to get the voters convinced, and help community groups to convince their politicians to do something about it. You can also use cost-benefit studies to get across the message about the benefits of prevention and of managing now, and explain that $\$ 1$ spent today means $\$ 100$ saved in the future. 


\section{Introducing invasives does not increase biodiversity!}

Be ready to counter the argument that introducing a whole bunch of new species to your island is a good thing 'because it increases the biodiversity'. Biodiversity is a global concept, whereas increasing local diversity by introducing species that are common elsewhere can actually reduce global biodiversity by causing the extinction of endemic species that are found only on your island and nowhere else in the world.

\section{Everyone has a role to play}

Invasive species are a problem in pretty much every island in the world. This is not the fault of the government or any one group, but results from uninformed, misguided or uncaring behaviour throughout society. Remind people that individuals are not powerless - each citizen can combat invasives through their own decisions and behaviour. What plants they choose for their garden, what pets or animals they choose to keep and how they look after them, how they manage their land - all these are things each person can do responsibly. Also how they vote, what environmental organisations they give money or time to, and what they teach their children, friends and neighbours, all have an effect beyond themselves. Convince people of 'the power of one' in campaigns, such as against sneaking animal and plant products or seeds back from their holidays; consider a Voluntary Code of Conduct for such things. And set an example: apart from your job battling invasives, avoid planting them in your garden, keeping them as pets, or taking fruit of invasives to islands where they are not present!

\section{Difficult customers}

How to overcome resistance on 'conflict of interest' species or unpopular management techniques

One person's pest is another person's food, pet, or pretty garden plant. Every ocean region has species like this. Pigs are one of the most controversial invasives in the Pacific because of their importance to islanders' food supply and history, and their enormous impacts on island ecosystems by changing forest structure and tree species composition, and predating native animals including sea turtle eggs, ground-nesting seabirds and flightless landbirds. Locally, each island may have its own special cases, such as the introduced macaque monkeys on Mauritius, notorious predators of endemic wildlife but beloved by some people and even promoted as a tourist attraction.

Another kind of conflict centres on the public acceptability of management techniques. Most invasives management involves killing things, which is distasteful to most people, including conservation workers who may be unwilling to use such techniques, owing to their own beliefs as well as fear of public backlash. This kind of opposition can be expressed violently by elements of animal rights groups, and becomes much stronger and more widespread when a management technique either involves killing large numbers of a popular species (like macaques or cats) or is perceived as likely to have direct impacts on the human population, such as by herbicide getting into drinking water or rat poison being eaten by pets or children.

Dealing with such situations obviously requires much care, time and investment. In some cases you might be able to get the support of an influential local politician to facilitate a project likely to be unpopular with the public (e.g. eradicating feral cats, prohibiting some animal imports), but often it will be more effective to work from the bottom up. 
The key points are persistence, patience, personal relations, sympathy and understanding. It may take a long time - years - to convince the general public, but focus on them first. In particular, identify the key people affected by the proposed project and also those who hold influence (these may not be the same people so you may need two different approaches). Beware of community meetings - you may have to organise some but never rely on them for changing opinion. Meetings on controversies are usually dominated by a vocal few who will easily counter your reasoned arguments with rhetoric, leaving you with even less support than before the meeting. Instead, use meetings to get to know people and to ask them questions; identify the vocal opponents and their concerns, and resist the urge to try to persuade them right there. Then talk to people individually as far as possible. Get to know people, and talk to them over and over again. Learn about their concerns and take them seriously. Try to discover and understand deeper differences between groups in the community, which could influence their judgment on this particular issue. Consider carefully how best to influence key objectors, either directly by talking to them, or by persuading the majority to convince them. Be prepared to discover that your initial key arguments may not carry much weight with objectors, and you may need to find reasons and explanations that they will understand, identify with, accept and support. Adapt your proposed techniques to deal with objections that you can't overcome by talk.

All that is a lot of work, but if your project is high priority, it's worth it. In fact it's essential - bear in mind that it will be hard to convince any funding organisation to pay for a controversial project. Don't try until you have the public's backing. Once you have public (including political) agreement for the work, finding funds becomes easier. And with local people whom you now know well supporting you, project implementation goes much more smoothly.

The consultations for rodent eradication on Lord Howe Island are a good example of the pitfalls and eventual success of this process: <http://lhirodenteradicationproject.org/the-project/communityengagement/>. A good flow chart for planning consultations is given by Novoa, et al. (2018: see simplified version below), and a guide to conflict resolution by Madden and McQuinn, (2014).

Steps for ensuring full consultation and engagement:

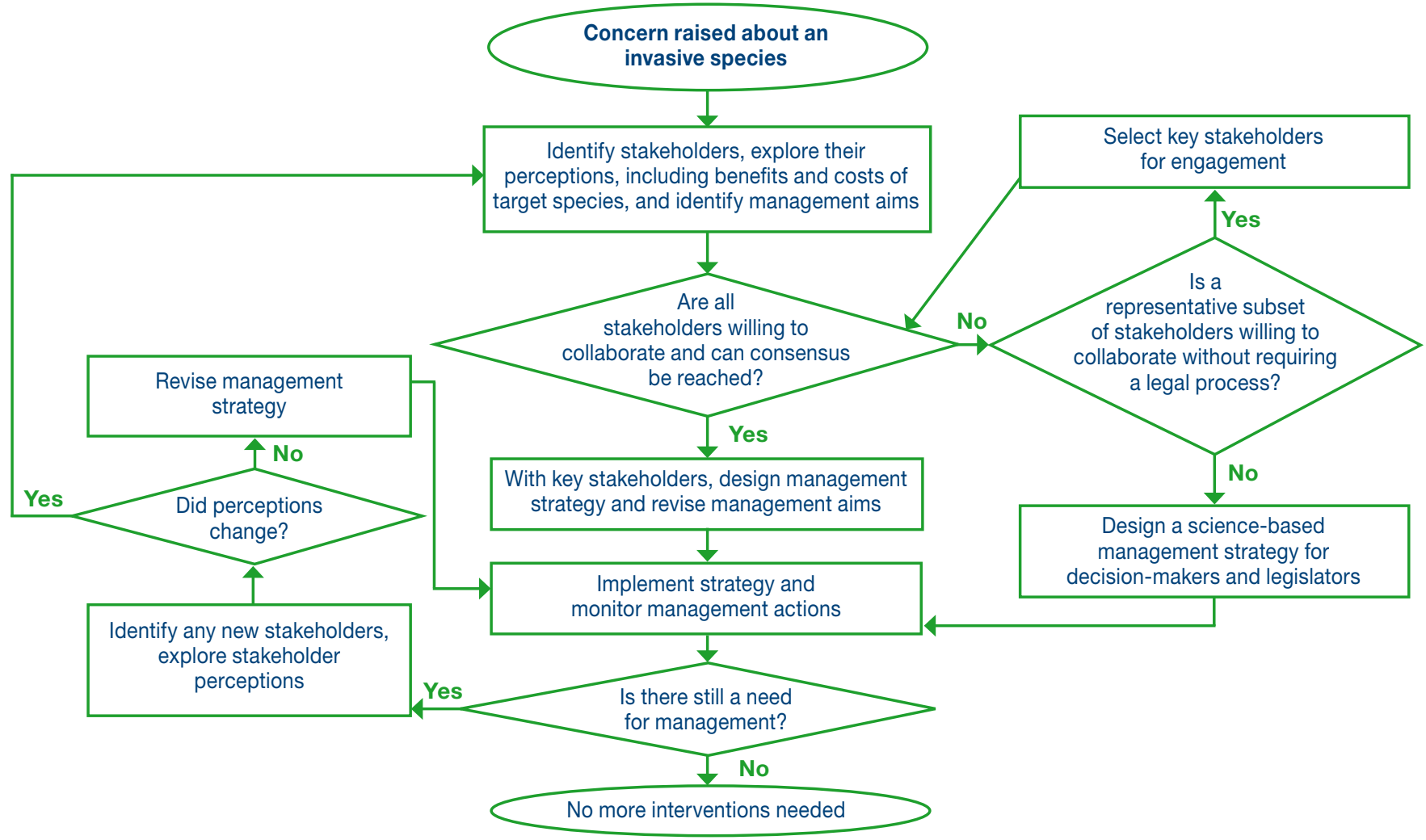




\section{How to mainstream}

\section{Influence at the top}

There is often a disconnect separating the 'technical people' (in government departments and NGOs) from the policy-makers, and this is often the greatest barrier to getting invasives management onto the national agenda. Governments already have their priorities, and if invasives are not already among them, you will be asking the government to reduce emphasis on its publicly announced priorities, in order to provide resources for tackling invasives. For this reason it is important to integrate invasives into existing government priorities (e.g. food security) by working within the government's priority-setting system to get them included. Figure out how to make your priorities mesh with your government's stated priorities and existing plans, and demonstrate the synergies to government officials. Make it clear to the government what you can offer them (e.g. training staff in various departments, writing public awareness messages, supporting a consultant to draft a national ISSAP etc.) and what you are asking for (e.g. review and update of legislation, hiring additional enforcement officers, treaty extension etc.). Be specific - vague requests for support will be only vaguely supported. Remember that the usual four to five year legislative terms are not very helpful for long-term planning, but work on long-term programmes where necessary and be prepared to lobby when the government is about to change. Getting an ISSAP signed officially and publicly endorsed by politicians on all sides will make it less likely to disappear when a new party takes over. But to do all that, you need a sympathetic ear at high level - not always easy to find, but once you do, that person's influence can lead to a dramatic increase in resources for your programme. Try to mainstream these Guidelines into national policy too, because once they become an accepted policy instrument you can use them to back up your plans more strongly.

\section{Integrate invasives management into other plans}

Make contact with other important sectors, such as sustainable development planning, land-use and agricultural planning, trade, transport and port management, protected area management, and climate change, and work with them to try to integrate invasive species into their management plans. One way to do this is by forming a multi-sectoral invasive species committee (more on this below, p. 23). Don't neglect the conservation sector - work with conservation departments and NGOs to integrate invasives management into plans for protected and conservation areas, and for threatened species. Some conservation managers still do not take invasives seriously enough to include their management in overall site management. The biosecurity sector can also be hard to penetrate, with a historical focus on agricultural pests only. Try to get all kinds of species covered by biosecurity control plans, even species not yet called 'invasive' (see 'Risk assessment' below, p. 29-30).

\section{Integrating with plans for global change}

Several kinds of global change and trends affect islands and favour invasive species. They can be used to raise the profile and importance given to invasive species management.

- Climate Change can favour invasive species by disturbing ecosystems, because many invasive species are pre-adapted to take advantage of disturbed areas, including those produced by 'natural' disasters. Further, temperature rise and changes in rainfall patterns may stress native vegetation and animals, whereas invasive species tend to be highly adaptable (one of their features that makes them invasive), so they may be favoured. Awareness of this adaptability makes a strong argument for integrating invasive species management into national climate change mitigation and adaptation programmes. 'Natural' disasters may increase with climate change, but their impact on invasions can be reduced by planning to minimise habitat disturbance and restore native vegetation in degraded areas. Further, invasive species management can help maintain or restore ecosystem integrity, and thereby increase resilience to climate change. This is a strong argument for incorporating invasives management into programmes for ecosystem-based adaptation to climate change, which are not only environmentally sound but may provide access to significant funding. 
- Land clearance. Clearing of large areas of native vegetation for large-scale crop production or mining also favours adaptable invasive species. As invasives management is needed to reduce land degradation as well as to tackle the invaders themselves, one can convincingly argue for the inclusion of invasives management into land-use planning.

- Transport. The worldwide increase in trade, travel, transport and tourism is the main driver of the spread of species that may become invasive. Development of new roads, railways, waterways, and air and shipping links increases the movement of people, freight and invasive species. Also, new roads, railways and waterways allow invasives to spread in the disturbed areas along them. Argue for including improved biosecurity measures in planning for the transport, trade and tourism sectors.

- Leisure, gardening, pets and the internet. Increases in leisure time and the expansion of tourism facilities result in increasing use of non-native ornamental plants, while gardening for food and herbal remedies also increases demand for less commonly used species. Through the internet, it's possible to order all sorts of seeds, even live animals. The pet and garden trades are now among the biggest drivers of introduction of new species worldwide. Argue for strengthening biosecurity and risk assessment systems for the horticultural, pet and tourism industries and for interception of organisms sent by mail.

\section{'Self-help' - how to develop regional networks}

Despite improved e-communications, people working on invasives on islands are hampered by the great distances and ocean barriers that limit personal contact and the transfer of experience from one group to another. Extra effort is needed to overcome 'island isolation' by developing regional coordination and joint action groups, and networks for exchanging news, information, experience, alerts, job announcements, and requests for assistance. Such networks can effectively produce collaboration and build capacity through staff exchanges, and greatly help in solving problems.
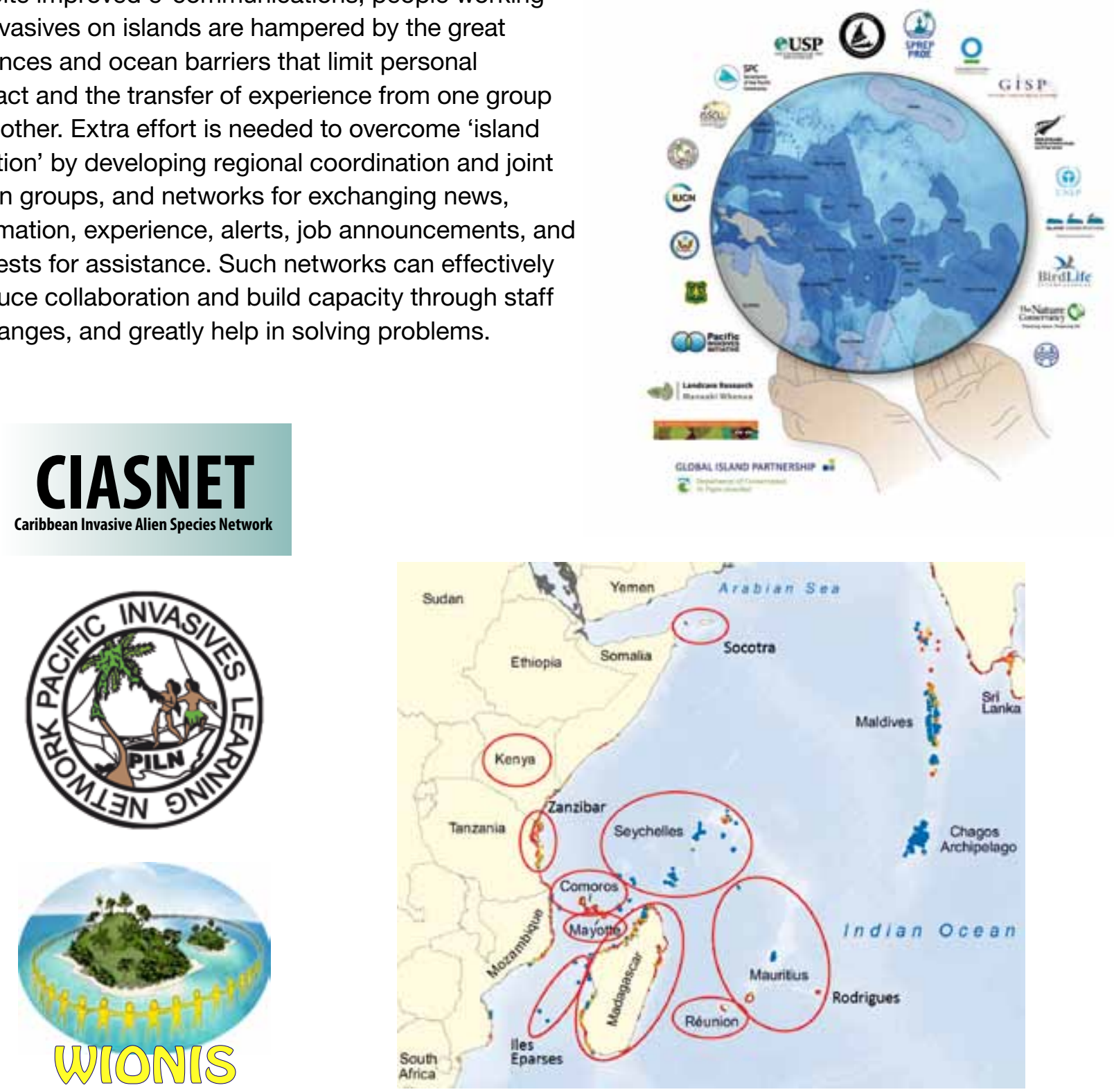


\section{The Pacific example}

The Pacific (Oceania) provides a good example of enthusiastic, highly inclusive and effective regional invasives coordination, supported by a robust regional institutional framework comprising regional service agencies, a professional network, a partnership of organisations that work on invasives issues and two email distribution lists.

Two regional inter-governmental agencies support their member countries and territories in managing the Pacific environment and threats to it. The Secretariat of the Pacific Regional Environment Programme (SPREP) provides support for protecting and improving the natural environment, while the Secretariat of the Pacific Community (SPC) promotes sustainable economic development through support to the agriculture, forestry, fisheries, health and other sectors. Both have invasives programmes.

Nature conservation is coordinated in the region by a network of NGOs, donors and others, known as the Pacific Islands Roundtable for Nature Conservation (PIRT), which serves as a forum for collaboration, and has the official endorsement of the Pacific island governments. PIRT conducts its activities through working groups, and the PIRT Invasive Species Working Group is known as the Pacific Invasives Partnership (PIP). PIP comprises c. 40 regional and international agencies working on different aspects of invasives in the Pacific, and PIP coordinates planning and assistance from these agencies to Pacific islands, for more effective invasive species management. PIP meets annually and its members develop a joint annual action plan. PIP is coordinated by SPREP, while the PIP Chair rotates among the member agencies.

The Pacific Invasives Learning Network (PILN) is a professional network based around country teams that include representatives of both governmental and non-government agencies. PILN membership is also open to individuals. Like PIP, PILN is managed by a coordinator hosted by SPREP. PILN members use the network to share skills, knowledge and news, and make requests for assistance. PILN is the network for in-country practitioners, while PIP is the partnership for agencies wishing to help them, so PILN is a member of PIP in order to facilitate links between the 'users' and 'providers' of invasives services.

The Pacific Invasives Initiative (PII) is a small but effective multi-disciplinary team of invasive specialists, working to strengthen capacity in Pacific islands for the effective management of invasive species, partly by leveraging New Zealand and other external expertise. PII is also a PIP member.

SPREP and PIP both have 'developed country' members with interests in the region (Australia, France, New Zealand, the United Kingdom and the United States), which contribute to invasive species management through their aid and development programmes, for example by funding SPREP and other regional initiatives, and providing experts, training and research services.

The Pacific is by far the largest ocean on earth, with more islands than all the rest put together. Sub-regional coordination is therefore also helpful, particularly at policy level, and the Micronesia and Melanesia Regional Invasive Species Councils have been established for planning and coordinating between islands within those regions. They advise on invasive species to the highest levels of government in their islands, including heads of state.

All that may look complex, but it works! And with so many involved, there's always someone to keep the collaboration ball rolling.

The Guidelines for Invasive Species Management in the Pacific (SPREP 2009) has been the framework for action by all of the countries and territories of Oceania and all of the above networks and organisations, including the PIP member agencies. You can use the global Guidelines that you are reading now in the same way.

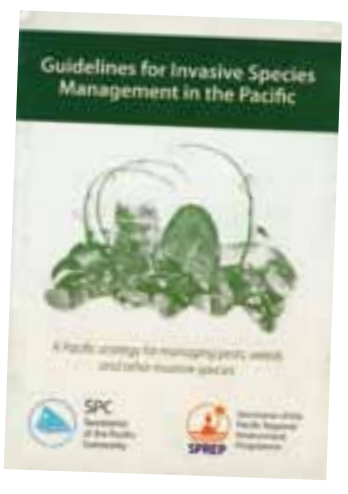




\section{How to start your network: from local to regional}

Aside from their role in coordination between islands, networks also provide an invaluable platform for different sectors to talk to each other and coordinate work within an island or country. There is often a barrier between the environment sector and agriculture, forestry and quarantine, and PILN's first steps were to encourage the formation of in-country teams, which brought all these sectors around the same table, allowing them to discover their shared interests and understand each other's needs. Bringing in customs and quarantine is essential, as they need to expand from their traditional role focused on plant and animal health and agricultural pests, to covering non-native species of environmental concern. Then, bringing together the PILN teams from different islands (bottom-up, to form PILN) combined with bringing together the main regional agencies (top-down, to form PIP), were the crucial elements in creating the regional framework described above. So an idea to form a regional network can be put into practice very effectively by starting at country level, talking, consulting and encouraging local invasive species committees or similar groups to form, and then making the inter-island links.

\section{Two essential elements: real meetings and an enthusiastic coordinator}

Recognising that lessons can be learnt from neighbours, and setting up joint actions with them, plays a big part in creating and cementing the network, as does developing friendships at face to face meetings. Such meetings seem essential, even in these days of social media and the internet: getting to know people personally is the best way to break the ice, develop confidence to ask each other for help, and arrange exchanges. An enthusiastic network coordinator also seems to be indispensable: someone who can continually promote and encourage. No matter how much one tries to 'get the members to take charge', it has to be actually part of the job (not necessarily full-time) of one person to keep the messages flowing on the email list, turn meeting ideas into meetings and generally keep the networking going. The PILN coordinator was initially on temporary contracts but became part of the role of a permanent post in a regional organisation, and this transition seems essential. Networks with an active coordinator remain active, but without someone enthusiastic and dedicated in that role, they stagnate. However, apart from the need for a coordinator, perhaps with a small travel budget, network maintenance does not need lots of money.

\section{What does a successful network look like?}

- Network coordinator (not necessarily full-time) with this role as part of their job (ideally employed by a regional organisation).

- Frequent, relevant e-communications and occasional network meetings.

- Strong in-country multi-sectoral invasives teams or committees, meeting regularly because they value the exchanges.

- Regional joint planning group for identification of joint priorities and collaborative actions.

- Professional links between workers on different islands, which develop into firm friendships.

\section{To what extent have other ocean regions achieved this?}

The Western Indian Ocean Network on Invasive Species (WIONIS) was inspired by the Pacific experience, but began in a fundamentally different way. Agreement to start a network came at a regional meeting in 2012, and WIONIS started regionally, without first forming a strong base of national teams. The network was initially supported by a coordinator employed on a regional invasives project, funded only for its first six years. WIONIS developed a more active email list than PILN, but still with many contributions identified and circulated by the coordinator. Some of the WIO islands have multi-sectoral invasive species committees, but these do not have institutional commitments to the regional network, and therefore the key element of inter-island joint prioritisation and planning is missing. In comparison with the Pacific, the links between the island committees are less effective, with fewer regional meetings on invasives, and little joint action. 
In the Caribbean, the member countries of CARICOM (the Caribbean Community) have several coordination bodies, including the Caribbean Agricultural Health and Food Safety Agency,

Caribbean Plant Health Directors Forum (CPHD), Greater Caribbean Safeguarding Initiative and Caribbean Invasive Species Working Group (CISWG), whose main emphasis is on animal and plant health and food safety systems in the context of trade facilitation, and the CISWG has been inactive for some years. Other regional initiatives carry out some actions, such as CAR-SPAW-RAC (see 'Resources' p. 39) but in general, cooperative invasives initiatives are not focused on joint action. The Caribbean Invasive Alien Species Network (CIASNET) covers all islands and all aspects of invasive species in or threatening the Caribbean, via its carib_ias_threat email distribution list. But in order to attain the strength and influence enjoyed by PIP and PILN in the Pacific, CISWG needs to be revitalised, while CIASNET and CPHD may need to strengthen linkages with the more powerful groups managing agricultural and food safety. A major regional project or initiative might achieve that, but there is also a need for a permanent coordinator.

The Initiative on Invasive Alien Species in the French Overseas Territories (FOTs) was launched in 2005 by the IUCN French Committee (see 'Resources' p. 39), with a full-time project officer, and local coordinators in each territory (recognised experts or natural resource managers). Its first results included an inventory of invasives and their impacts in all FOTs, regional workshops in the Caribbean, the Pacific and the Indian Ocean, and the production of technical guidelines and information leaflets for practitioners. This initiative overlaps with and complements the regional networking in each ocean region and benefits from national (French) support rather than depending on a regional organisation.

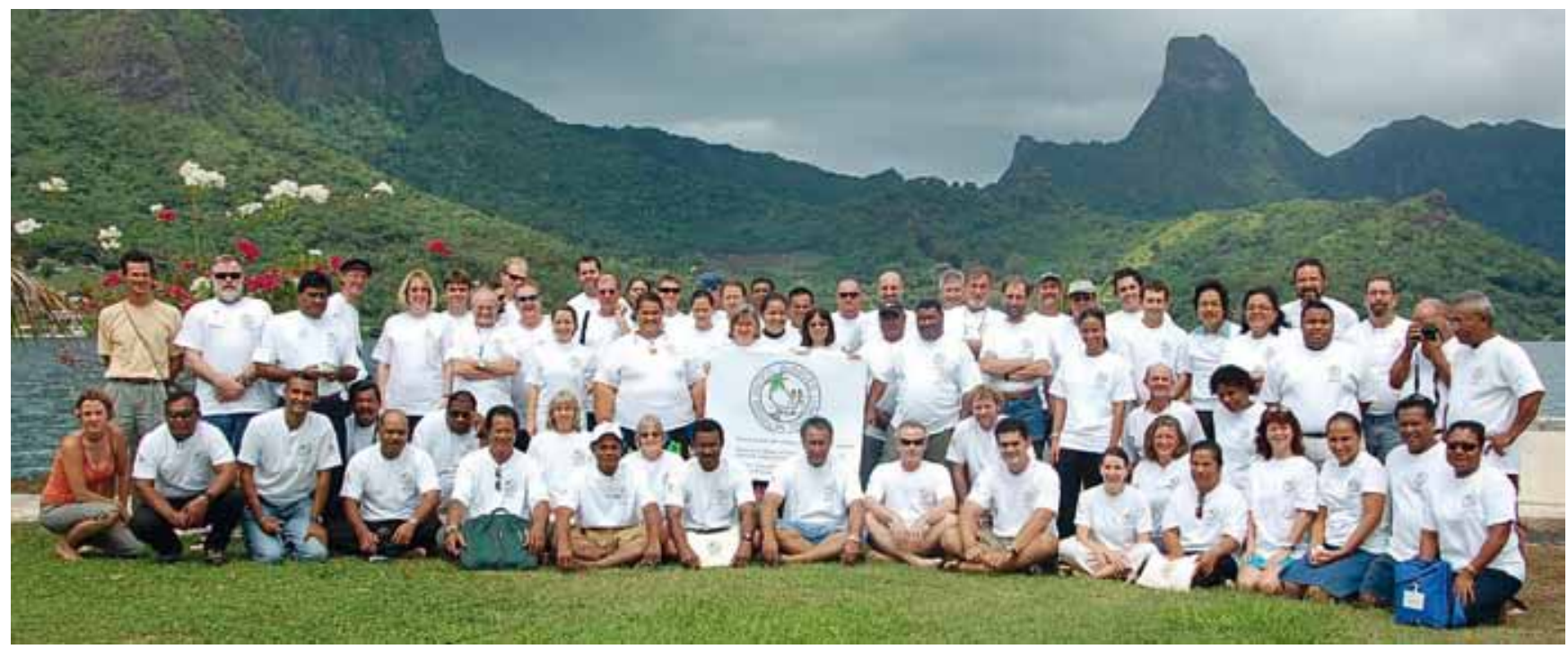

Another successful network meeting... 


\section{How to: write the plan, prioritise, make decisions}

This section is mainly about programmatic planning: writing and using strategies, policies and action plans, to guide organisations responsible for invasive species prevention and management. But a first step is to decide who writes the strategy? A single department or organisation can plan for its own programmes, but a national, regional or island strategy needs to be led by a multi-institutional planning effort. For example, a National Invasive Species Strategy and Action Plan is ideally put together by some kind of National Invasive Species Committee (NISC), while similar groups on a larger scale can write regional plans, or on a smaller scale produce plans for individual islands.

\section{How to form and operate a National Invasive Species Committee}

You can start with any pre-existing team or informal group of colleagues in different agencies. In the Pacific experience outlined on pp. 20-21, the PILN team (including government departments, NGOs and others) often became the NISC, and the teams that were stronger at the technical level quickly became well bedded into national planning processes, so they were able to influence decision-makers - the bottom-up approach works.

A successful NISC needs its own Coordinator, preferably someone at technical level, who has invasives as part of his/her responsibility and who can actively lead the planning process. The committee Chair can be a higher-level person, such as a department head, to give the committee credibility and influence with the government, but ideally the Chair should also be enthusiastic about invasives management. Where leadership is weak, the committee is weak - champions play a big role, including in starting the committee in the first place, and the more of them the better. They may include the NISC Coordinator and Chair, but the involvement of other active and enthusiastic individuals, including from NGOs and the private sector, greatly helps to encourage and promote ideas. Some kind of charter for the committee can ensure clarity of purpose, roles and procedures. Good committees contain people who can influence their own organisations (and reach across organisations) to drive change and ensure that invasives management is integrated into departmental planning and budgeting and from there embedded into national planning and budgeting. When the NISC is incorporated into the government system, it may be in a position to receive government resources for operations, as well as having a stronger voice, and it can then take a national leadership role for invasive species management.

Keep it active, relevant, interesting and useful

To prevent apathy, committees need to avoid sticking to a repetitive format and meeting for the sake of routine when there's not much to say. Make sure to meet when something needs to be discussed, but also at some sort of regular interval (a couple of times a year) even if nothing much is on the agenda, because the mere opportunity to be in the same room will often stimulate people to raise issues that they might not otherwise. For this reason, meetings need to be as friendly and welcoming as possible, with an egalitarian and relaxed atmosphere, and a sympathetic chairperson who encourages everyone to contribute.

\section{How to write an Invasive Species Strategy and Action Plan (ISSAP)}

\section{Why write an ISSAP?}

Because there are never enough resources to do everything. An ISSAP can:

- bring different sectors and the wider community together to agree on priorities,

- show that you have sat down, thought strategically, and are ready for action,

- bring invasives to the attention of decision-makers and funding agencies,

- provide a strong argument to persuade them to finance action on the priorities that everyone has agreed on. 


\section{Be inclusive}

A NISC is the ideal group to lead the writing of a national ISSAP. Adopting and extending an existing planning process (such as the NBSAP process) can help to get a NISC and a plan moving, because (part of) the planning team will already exist. But make sure that representation is widened to include any key missing sectors or agencies. It's essential to include all sectors engaged in any aspect of invasive species use or management, including government agencies, NGOs and research organisations working in environment, agriculture, horticulture, forestry, aquaculture, quarantine, weed and pest management services, health, transport, trade, tourism, law enforcement ... - get as many as you can. Many of these will be on the NISC, but you may need to invite related sectors such as land-use planning, climate change and economic development, and if you can interest the finance ministry or prime minister, so much the better. A national ISSAP should ideally be linked to the country's NBSAP or National Development Strategy, and should be endorsed by government. But whether national, single-island or sectoral, the preparation of an ISSAP must be inclusive, so that all those responsible for invasives think of it as 'their' work and 'their' plan.

\section{Learn from an expert and use these Guidelines to help}

A principal function of these Guidelines is to guide all steps of the construction of an ISSAP. Use them to make sure you don't forget anything. The best ISSAPs are prepared by stakeholder discussions facilitated by an expert in both invasives and planning (not just in planning). Such a person helps a lot by providing expert advice as well as with facilitation and compilation of ideas. Expert help can spot gaps later too, so it's always a good idea to have plan drafts reviewed by an external expert or group.

\section{Content and organisation}

Whether planning for an island, an island nation, or even an individual agency, aim for three main sections to the plan: Introduction, Strategy and Action Plan.

The Introduction to a good plan consists of a 'situation analysis', which outlines what is known and what is not known about invasives in the islands of concern, their impacts on natural areas, threatened and endemic species, livelihoods, health and the economy, potential future impacts if invasives are not managed, likely impacts of species not yet present in the islands but which could easily be introduced, and pathways of introduction. It also reviews past and present management action, identifies major gaps in the programme and problems that make management difficult (lack of policy, legislation, organisations responsible, information, experience, experts, funds, links with donors or technical assistance), and identifies the organisations to be involved in management (implementing the plan), their roles, responsibilities and capacities, and the laws, mandates and financial resources available to help.

The Strategy itself can then be based around overall Goals, intended to address the problems and gaps in knowledge and action identified in the Introduction. Each Goal may be approached by a series of more detailed Objectives. The Strategy should also state who is responsible (often the NISC) for leading it, monitoring progress, evaluating success, reporting back to stakeholders on progress or lack of it, and following up the plan when its implementation period ends.

The Action Plan is the most important part of a successful ISSAP, and presents the specific priorities selected for action within the duration of the ISSAP. Every Action should contribute to reaching one or more Objectives of the Strategy, should be precise and specific and should indicate: who is responsible for it (government agency, NGO, community group... only include an Action if the designated agency agrees!), when it will be carried out (defined period), how much it will cost and where the money will come from. Progress on the Actions should be monitored, to feed back into later Action Plans. The ISSAP should include Actions on evaluation and further planning when the ISSAP's lifetime draws towards its end. 


\section{Principles for writing an ISSAP}

- Consider all 10 Thematic Areas of the Guidelines Checklist

- Be inclusive - the process needs to be fully participatory
- Include key sectors and agencies

- Link to NBSAP and/or National Development Strategy

- Plan for the future - what happens when this ISSAP ends?

\section{A template for an ISSAP}

\section{SECTION 1: INTRODUCTION with 'situation analysis'}

This section covers the background, action taken, action needed, and areas needing attention.

- Summarise what is known about introduced and invasive species in your islands (add an appendix with species lists, indications of impact for each one). Are the lists fairly complete or seriously incomplete?

- Summarise what is known of: (i) current impacts on natural areas, threatened and endemic species, livelihoods, health and the economy; (ii) potential future impacts if invasives are not managed; (iii) likely impacts of species not yet present in the islands but which could easily be introduced; and (iv) pathways of invasion. What knowledge is missing?

- Review past and present management of invasives. What action is lacking, and why is it lacking? Use the Guidelines Checklist to review current programmes and identify gaps.

- Identify which institutions should be involved, what is their capacity (including budgets), and what policies, laws and regulations are in place? What is missing?

\section{SECTION 2: STRATEGY - defining Goals and Objectives}

- Goals are where you want to be in the future - what is needed to fill the gaps and deal with the problems identified above?

- Objectives are what you want to happen in order to reach your goal.

An example of a Goal and its Objectives might be:

Goal 1: The rate of arrival of new species in our islands is reduced.

Objective 1.1 Quarantine branch applies risk assessment to all proposed new introductions and establishes permitted and prohibited lists of organisms and products.

Objective 1.2 Quarantine and customs staff inspect $10 \%$ of all containers and $100 \%$ of passenger luggage for organisms, and safely decommission all organisms intercepted.

\section{SECTION 3: ACTION PLAN - defining Actions to attain the Objectives}

- For each Objective from the Strategy, identify one or more Actions.

- Every Action should be 'SMART' (Specific, Measurable, Assigned to someone, Resourced, and Time-limited).

- If you don't already have the assistance or funding committed, write the Action like this: "Seek assistance/ funding from $X Y Z$ to do $A B C . . . "$

\section{Examples of Objectives and their Actions might be:}

Objective 1.1 Quarantine branch applies risk assessment to all proposed new introductions.

\begin{tabular}{llllll} 
& Action & Responsible & Complete by & Cost & Source \\
\hline 1.1a & $\begin{array}{l}\text { Train quarantine staff in risk } \\
\text { assessment }\end{array}$ & Quarantine Branch & May 2020 & $\$ 10,000$ & $\begin{array}{l}\text { Assistance from neighbouring country } \\
\text { Xyz }\end{array}$ \\
\hline 1.1b & $\begin{array}{l}\text { Include risk assessment procedures } \\
\text { in biosecurity legislation }\end{array}$ & Dept of Agriculture & August 2020 & - & Within government budget
\end{tabular}

Objective 1.2 Quarantine and customs staff inspect $10 \%$ of all containers and $100 \%$ of passenger luggage for organisms, and safely decommission all organisms intercepted.

\begin{tabular}{llllll}
\multicolumn{1}{l}{ Action } & Responsible & Complete by & Cost & Source \\
\hline 1.2a & Install X-ray machine at main airport & Quarantine and Customs & March 2021 & $\$ 10,000$ & Project X funded by donor Y \\
\hline 1.2b & Increase container inspection rate to & Quarantine and Customs & July 2020 & $\$ 30,000$ & Government budget \\
& $10 \%$ by recruiting 2 new staff & (1 new staff each) & & per year &
\end{tabular}


The Strategy and Action Plan should consider all 10 Thematic Areas of the Guidelines Checklist (pp. 1-12), from setting up the foundations for action, through understanding the invasives, prioritising activities, preventing introductions, managing established invaders, and restoring damaged biodiversity and other values.

\section{Plan for success!}

People are inspired by early successes, even small ones, and are then more likely to feel that it is worth being part of the team, the NISC and the network. Therefore, choosing realistic targets is an essential part of planning for success (see pp. 29-36). Most importantly, think beyond the plan - this is all about action. Invasives are often a low priority for island governments, who may talk about the issue and make plans, but not provide enough money to implement them. On paper, island countries and territories often look great in terms of strategies and plans, but they don't actually do much invasives management because the plans are too often not backed up with resources or real commitment.

To get over this, it's essential to be realistic and practical. Aim to ensure that actions can get done, rather than trying to be too ambitious. A useful catch-phrase is 'turning words into action' - not easy but that's the aim. Strategic planning can end up producing an impossible wish list, but successful and inspiring planning focuses on what can actually be done, in the first instance with existing resources, and then progressing to more ambitious targets that need extra money to tackle. Start small with the 'easy targets', and make sure to hit some of them. For example, it is far too common to decide that a widespread invasive plant like Merremia vine (Pacific) or Strawberry Guava Psidium cattleianum (in the Indian Ocean), or a common introduced animal pest like mongoose or myna birds are the priorities, because these are 'obvious problems'. But trying to tackle these is discouraging and gets nowhere when resources are inadequate. Better to select some early-infestation species where complete eradication is possible, at the same time improve your island biosecurity system, and build up gradually to more difficult problems.

Then you can celebrate successes, even small ones, and use them to raise support, by showing how it can be done again, bigger and better, and how others can do the same. Exchanges and workshops help with this, and extend beyond the local context to regional level and beyond. Communication is very important, even of failures. A newsletter or web site can be a good tool for this, starting low-key and easy. Maintaining it and encouraging contributions is a part of the indispensable job of the coordinator.

\section{Model ISSAPs}

ISSAPs exist for many islands, many of the recent ones based on recommendations from the Convention on Biological Diversity, such as the Aichi targets (see 'Resources' p. 38). Many good ISSAPs can be found online and used as models, while additional guidance on writing an ISSAP can be found in the Pacific Battler Resource Base (see 'Resources' p. 38).

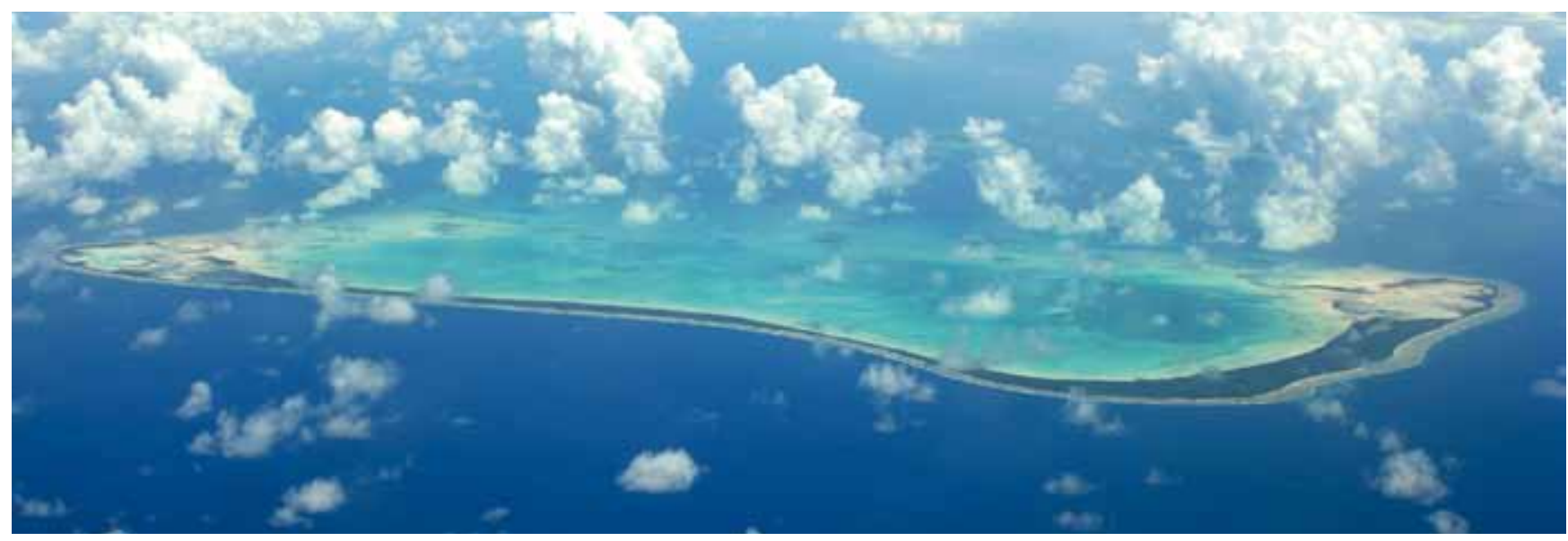

Maiana atoll, Kiribati. 


\section{How to prioritise}

Prioritisation is part of decision-making throughout the planning process, but happens most clearly at two main stages:

- Prioritising areas of action. These higher-level planning decisions are considered under section A1 of the Guidelines Checklist.

- Prioritising species, pathways and sites for action. These work-planning decisions are considered under section B2 of the Guidelines Checklist.

\section{Prioritising areas of action}

The major recommendation here is to use something as an aid to memory, to make sure that nothing important is overlooked. This is precisely the function of the Guidelines Checklist (pp. 1-12). See Thematic Area A1 of the Checklist for general hints and principles, and use the entire Checklist as a basis for choosing which areas are important to your country, island or agency. Use it also to identify gaps and neglected areas in your current invasives programme.

The Checklist will help you to consider, include or leave out from your plan each particular area of action. For example, your island might be most concerned at present with biosecurity (keeping things out), than with, say, biological control, or if you are planning for an agency you will obviously be most concerned with activities that fall into your agency's official remit, or your NGO's specialist area of technical expertise. If you are writing an ISSAP, you will need to consider carefully what you will leave out (for now), because although ideally you need to cover everything, it's essential to be realistic and only plan for what you think you might be able to pay or find funds for. You can use the Checklist to help you make short-term and longer-term priorities, even though you might not yet have funds for the longer-term ones.

\section{What do we do well, and what not so well?}

A number of gap analysis studies (e.g. Doherty and Boudjelas, 2010 for the Pacific; Key, 2017 for UK Overseas Territories; Boudjelas, 2018 for Western Indian Ocean), together with informal consultations for these Guidelines, show in general terms how well or how poorly the different areas of action that make up the 10 Thematic Areas of the Guidelines Checklist are covered by ISSAPs, similar plans, or island invasives programmes. Almost uniformly across islands and regions worldwide, coverage from best (green) to worst (red) is as follows:

\begin{tabular}{|c|c|c|c|c|c|c|c|c|c|}
\hline C2 & A2 & A3 & B3 & A4 & C1 & B2 & B1 & A1 & C3 \\
\hline Management & $\begin{array}{c}\text { Generating } \\
\text { support }\end{array}$ & $\begin{array}{c}\text { Building } \\
\text { capacity }\end{array}$ & Research & $\begin{array}{c}\text { Legislation, } \\
\text { policy }\end{array}$ & Biosecurity & Prioritisation & $\begin{array}{c}\text { Baseline, } \\
\text { monitoring }\end{array}$ & Planning & Restoration \\
\hline 1 & 2 & 3 & 4 & 5 & 6 & 7 & 8 & 9 & 10 \\
\hline
\end{tabular}

\section{Commonly neglected areas - don't forget them!}

There are some glaring lessons in the table above.

- Although Management of Established Invasives (Thematic Area C2), Generating Support (A2) and Building Capacity (A3) are usually covered in most invasive species plans or programmes, in sharp contrast, Biosecurity (C1), which is the most cost-effective and safe way to manage large numbers of invasive species (by keeping them out), is usually poorly covered, on most islands everywhere. It is usually under-funded, often directed only at agricultural pests, and sometimes completely neglected. When planning, consider 'horizon scanning' (what species are likely to arrive and how they might arrive), formal quarantine (border control) systems, and also informal community-based awareness and biosecurity for protecting small islands. 
- Research (B3) and Legislation, Policy \& Protocols (A4) are usually considered in some way, but often not very well. Are you really doing enough on these? 'Research' can be seen as an excuse for no action, but properly applied research is essential to get management right.

- Prioritisation (B2), Baseline \& Monitoring (B1), and Planning (A1) are omitted from most plans and programmes. These three areas form the basis for making decisions and planning, which strongly suggests that:

- invasives planning is mostly being based on poor information (poor baseline data),

- invasives planning decisions are mostly made arbitrarily or subjectively, without objective prioritisation or following the basic principle of carefully choosing activities that you can achieve,

- we often don't know whether the projects have had any effect (no monitoring).

The most worrying aspect of the neglect of these areas is that it indicates that most plans are not very well thought out and most resulting invasives programmes are unbalanced. This prevalence of poor planning is the main reason for producing these Guidelines. Try to make sure that your planning is itself properly planned (A1) and prioritised (B2) - use the Checklist of these Guidelines, and make proper prioritisation an Action in your plan.

- Restoration (C3) is also usually omitted. It is closely linked to Monitoring (B1) because without monitoring we don't know what post-management restoration may be needed. Both Monitoring (B1) and Restoration (C3) are essential - try to make sure that both are included and funded.

Also, within individual Thematic Areas, the following elements are often omitted:

- Rapid Response to incursions (part of Thematic Area C1 Biosecurity), and Eradication (part of C2 Management) are in the long term the second-cheapest management methods (after prevention), but they are under-used mainly because governments and ordinary people don't see the value of managing a species until it has become a problem, whereas it's easier and cheaper to eradicate it before it does! Without fast action, eradication becomes too expensive or too difficult. Find a way to include resources for tackling new incursions as well as other feasible eradication projects.

- Biological Control (part of C2 Management). Modern biocontrol is usually safe if international guidelines are followed (see 'Resources' p. 40), but fear of it based on high-profile early mistakes (such as mongoose, myna, cane toad) made before biocontrol included risk analysis and specificity testing, often lead to it being omitted from plans. In reality, biocontrol can deal safely with many wellknown invasives on islands, especially invasive plants and insects - see 'Resources' (p. 40) for lists of successful biocontrol projects. Remember too that biocontrol can be cheap if your target already has well-researched control agents available. Try to consider some of the suitable targets, and convince people of the value of biocontrol through publicity showcasing successes and good science. And if you can do one project successfully (that means not just achieving successful control, but also with no bad consequences), it can radically change local public opinion.

\section{Some other neglected areas, which cut across all 10 Thematic Areas of the Guidelines Checklist, include:}

- Marine and Freshwater invasives (note that these Guidelines apply to all kinds of invasives). Make sure you don't forget what's invading your coastal and inland waters. If nothing has been done about aquatic invaders, the first step will be baseline surveys (B1). Toolkits on marine pest management (Hilliard, 2005; Jackson, 2008) can help with planning a marine invasive species programme.

- 'Native invaders'. Consider what to do about problem species that are native to your island (like many agricultural weeds, or Crown of Thorns starfish might be). Sometimes this is further complicated by doubts over whether a species is native or not (like the vine Merremia peltata in the Pacific). Consider if and how such problematic species should be dealt with by your plan.

When working through the Checklist in your planning sessions, it's worth giving special emphasis to the above areas that tend to be forgotten. Consider whether you can do something about them, and how to get resources to include them. 


\section{Prioritising species, pathways and sites for action}

This type of prioritisation decision is considered under section B2 of the Guidelines Checklist. There are several Risk Assessment (RA), pathway analysis and site-value analysis tools available to help you make decisions about which species, pathways and sites to manage, and a good review is given by McGeoch, et al., (2016). Why use these tools? - Because they help you predict impacts and use money wisely.

\section{Assessing the risk of SPECIES and prioritising them}

Risk Assessment tries to determine the likelihood that a species will become invasive in your island(s), and can be used in two ways: (1) to evaluate species not yet present on an island, so as to determine whether to permit or refuse their importation (border control or biosecurity); (2) to evaluate species already present, e.g. plants in cultivation, to determine which ones are most likely to become (more) invasive in the future, and help prioritise them for management. It can therefore be used to answer several different questions. A typical border control or quarantine department question might be:

\section{Someone proposes to introduce a new ornamental plant or crop species. Do we permit it to enter?}

While questions about managing established introduced species include:

We have 500 introduced plant species in our island, and we know the top 10 invaders. But which of the many plants in people's gardens might become the next problem?

Risk Assessment for plants is usually termed "weed risk assessment" (WRA) and for animals and pathogens "pest risk assessment" (PRA). Risk assessment systems permit you to predict the invasiveness and impacts of a species before they take place. So you can decide to refuse permission to bring a species into an island, or you can decide to try to eradicate a species that is already there, which has not yet become a problem but probably will in the future if left unmanaged. In both cases you can act while it is still affordable, therefore, RA = wise use of resources. The ultimate aim of risk assessment is to help prioritise management actions. RA doesn't necessarily make the prioritisation decision for you, but prioritisation takes place after the risks have been assessed.

Some principles to remember when deciding what to tackle:

- Not all introduced species are invasive, and action should be prioritised to deal with those that are currently causing, or have the potential to cause, the most harm.

- To maximise effectiveness and value for money, invasive species risk assessment and prioritisation are fundamental and must be based on good science.

- Always apply the 'precautionary principle'. Where knowledge is insufficient to assess accurately the risk of a species becoming invasive, or its present or future impacts, it should be assumed that impacts will occur, and action should be taken to prevent the species becoming established or spreading. A precautionary approach assumes that any species imported to an island to be kept in ponds, pens, cages or gardens will eventually escape into the wild, and this is usually a realistic expectation! So plan accordingly.

- When prioritising species, pathways and sites for action, consider cost, effectiveness, acceptability, and future problems (e.g. possibility of reinvasion).

- Once you have chosen them, stick to the agreed priorities!

RA includes assessing a species' risk of entry, establishment, spread and impact, and assessing the efficacy and feasibility of management options. The results are then used to decide on or recommend action (including influencing decision-makers). Risk assessments use evidence that a species has been reported as invasive somewhere or has characteristics that usually lead to invasion, combined with knowledge about the island of concern compared with places where the species is invasive (climate, 
soils, vegetation zone, etc.). Evidence is scored numerically to indicate the likelihood that this species will become invasive in the island of concern.

For border control (decisions on whether to permit importation), all of the information used for the RA is about the species' behaviour elsewhere, and the resulting score is expressed as a management recommendation (i.e. 'probably safe enough, allow import', OR 'risky, consider further', OR 'certainly unsafe, prohibit import'). Some countries use RA results to generate lists of species prohibited for import (called 'negative lists' or 'black lists'). A safer, more comprehensive approach is based on lists of species that are allowed to enter ('positive lists' or 'white lists') with everything else automatically prohibited unless tested by RA and then explicitly permitted.

For species already present, local information about the species is also taken into account in the RA, and resulting scores are interpreted directly as priorities or expressed in terms of a classification of likelihood of becoming invasive. This kind of RA for established species is well developed for plants (=WRA) and is an excellent way to justify the early eradication of highly dangerous species (e.g. ornamentals) before they escape from gardens. Examples of RA systems are given in Resources, pp. 39-40.

\section{Assessing the risk of PATHWAYS and prioritising them}

There are many 'pathways' by which species may be introduced to islands, some unintentional, some deliberate, and the continuing growth in global trade, travel, transport and tourism has created many new pathways. A pest moth may be attracted into a lighted aircraft being loaded with passengers or freight at night; ants and toads can crawl into a shipping container and be on their way across the world a few hours later. Pets and the horticultural trade are two major pathways of deliberate introduction of new species that become invasives. Aquarium plants collected in Asia can be sold from a pet shop in Mauritius, and then get thrown out and washed into a drain that leads to a wetland. Once such pathways are identified, it may be possible to monitor and control them. A risk assessment used to assess the importance of different pathways of introduction is called a Pathways Analysis. By identifying particular pathways, risky goods etc. it allows you to answer the question:

What pathways need priority management in order to prevent known pests in neighbouring countries from entering our island?

The many possible pathways fall into the major categories given in the table opposite. Within an island region, it is helpful to exchange information about frequently detected species, recent arrivals of potentially invasive species, and their common pathways of introduction. Then you can monitor such pathways for expected species and try to prevent their entry or establishment. Pathways of deliberate introduction are controlled by regulatory approaches (e.g. licensing) and inspection. Pathways of illegal or unintended entry of new species are controlled by inspection and treatment of incoming vessels and aircraft, goods, construction materials, equipment (e.g. with soil residues), personal luggage, parcel post etc.

\section{Assessing the risk to SITES and prioritising them for invasives management}

Many conservation departments draw up lists of priority sites for protection or management of various kinds, usually based on their biodiversity value and threats to it, including invasives. Locally responsible agencies will of course prioritise work on the sites that they manage. However, more difficult choices may need to be made at national and regional scales, particularly regarding which islands (or other major sites) should be managed when resources are insufficient to do everything on all of them, as is usually the case. Formal prioritisation exercises are being done more commonly to facilitate such decisions. For example, the priority of an island for invasive species eradication can take into account its biodiversity value (number of rare or endemic species) and the feasibility of eradicating the target invasive species (based on island area, terrain complexity, human population and re-invasion risk). Almost 2,500 islands belonging to UK overseas territories were evaluated in this way by Dawson, et al., 2014), who give a good description of 
Pathways of introduction (= reasons, in the case of deliberate introductions). (Adapted from Wittenberg and Cock, 2001; Hulme et al., 2008 and IUCN, 2017b).

\begin{tabular}{|c|c|}
\hline & Pathway \\
\hline $\begin{array}{l}\text { RELEASE: } \\
\text { Deliberate introductions } \\
\text { direct to the wild }\end{array}$ & $\begin{array}{l}\text { - Game animals and fish released for hunting or a food source } \\
\text { - Releases to 'enrich' native flora and fauna (e.g. by acclimatisation societies or for landscaping) } \\
\text { - Biological control agents } \\
\text { - Erosion control, dune stabilisation, waste management etc } \\
\text { - Ecological analogues to replace extinct species or populations } \\
\text { - Introductions of threatened species to conservation refuges }\end{array}$ \\
\hline $\begin{array}{l}\text { ESCAPE: } \\
\text { Deliberate introductions with } \\
\text { no particular concern for } \\
\text { containment }\end{array}$ & $\begin{array}{l}\text { - Plants (including germplasm) introduced for agriculture, horticulture, biofuels, forestry or soil } \\
\text { improvement, including by development aid programmes } \\
\text { - Ornamental plants, pets, aquarium organisms and their live food, which escape or are } \\
\text { deliberately released into the wild }\end{array}$ \\
\hline $\begin{array}{l}\text { Deliberate introductions } \\
\text { to containment, which } \\
\text { unintentionally escape }\end{array}$ & $\begin{array}{l}\text { - Farmed animals, including aquaculture and mariculture } \\
\text { - Escapes from zoos, aquaria, botanical gardens and research facilities }\end{array}$ \\
\hline $\begin{array}{l}\text { CONTAMINANT: } \\
\text { Unintentional introduction } \\
\text { with a commodity }\end{array}$ & $\begin{array}{l}\text { - Seeds, invertebrates, parasites and pathogens in or on animals, plants and seed traded for } \\
\text { - Sgriculture, forestry, aquaculture and mariculture and bait } \\
\text { - } \text { mariculture produce } \\
\text { - Seed, invertebrate and pathogen contaminants of nursery plants and cut flowers } \\
\text { - Soil-inhabiting species transported in soil }\end{array}$ \\
\hline $\begin{array}{l}\text { STOWAWAY: } \\
\text { Unintentional attached to a } \\
\text { transport vector }\end{array}$ & $\begin{array}{l}\text { - Organisms on machinery, equipment and vehicles, including military } \\
\text { - Organisms in or on packing materials } \\
\text { - Organisms adhering to passenger and tourist luggage and equipment, e.g. angling gear } \\
\text { - Hitchhikers in or on cargo, including shipping containers } \\
\text { - Hitchhikers in or on planes } \\
\text { - Organisms in dry ballast, ballast water and ballast tank sediment in ships } \\
\text { - Boat hull-fouling organisms } \\
\text { - Organisms in or on synthetic marine debris }\end{array}$ \\
\hline $\begin{array}{l}\text { CORRIDOR or FACILITATED: } \\
\text { Unintentional introduction } \\
\text { facilitated by human activity }\end{array}$ & $\begin{array}{l}\text { - Organisms passing through artificial structures, such as fish through canals, animals } \\
\text { crossing bridges or passing through tunnels } \\
\text { - Organisms arriving unaided after having been introduced nearby by any of the above } \\
\text { pathways, or assisted to establish by human activities such as land-use change }\end{array}$ \\
\hline
\end{tabular}

the methods that can be used to prioritise islands for management. Useful data for prioritising islands are online in the Threatened Island Biodiversity database (Resources p. 39).

\section{How to select management goals for a species or site}

Once you have identified the priority species, pathways and sites that you want to work on, how do you choose what to do about them? Is the objective to eradicate the species completely from the island? Is that possible (= how much would it cost)? If not, is the species a potential target for biological control? Do you just want to keep the species out of high-biodiversity areas such as a national park? Or if the species is already widespread and common, do you just want to reduce its population and impacts in certain places such as on farms or in national parks? This kind of decision is choice of management goal, and is linked to but not always the same as choice of management technique (e.g. chemical control techniques can be used for either eradication or long-term population reduction - two different management goals). 
For choosing a management goal, a hierarchical approach should be adopted, in this approximate order of priority: IIIL

1. Prevention. Prevention is more effective and cheaper than managing established invasives, so excluding invasives by border control is the top priority (see Checklist section C1, pp. 10-11).

2. Eradication (complete elimination of the species from an island). If the impacts of the species exceed the benefits of having it on your island, determine if it can be eradicated completely from the island. Eradication success and cost can be predicted very reliably these days, at least for mammals and plants. Use a formal model to calculate cost and time required for eradication (e.g. Cacho and Pheloung, 2007; or IPMDAT). An eradication programme may be expensive, but it is a one-off cost and afterwards the cost of the pest and its management reduce to near-zero, though continued surveillance is needed to ensure that re-invasion does not occur. Eradication is therefore more effective and cheaper in the long run than permanent control of a pest population, and eradication should be considered whenever feasible, especially for new arrivals (see Checklist objective C1.4, p. 11) and species present only in small areas (see Checklist action C2.2c, p. 12). Eradication is most effective if a new arrival is detected early while still limited, so surveillance is important. Make sure that the strict criteria which must be met for eradication to succeed are met by your project (IUCN 2000; Parkes and Panetta, 2009).

3. Permanent reduction of population or its vigour (achieved by biological methods). Species that cannot feasibly be eradicated, especially those which have spread widely, should be considered candidates for biological control, genetic techniques or similar means of achieving permanent population or impact reduction (see Checklist actions $\mathrm{C} 2.2 \mathrm{~d}$ and C2.2e, p. 12), because these techniques also require minimal long-term investment after success has been achieved. If the invasive species is a plant or insect that is not highly valued locally, biological control may be an option. It can sometimes be used to control an invasive but useful plant species, because it only reduces competitiveness and impact - it does not eliminate the target species. Modern biocontrol uses very specific control agents (like fungi or insect parasites) that attack only the target species. General predators like flatworms, myna birds, cane toads, cats and mongooses should never be used for biocontrol because they usually do not control the pest as they have too much alternative food available, but they can cause extinction of defenceless native species. Safe biocontrol agents are available relatively cheaply for some pests and weeds, but if no known agent exists for your pest species, an expensive research programme will be required to find one.

4. Containment. Species that cannot feasibly be eradicated with resources available (use a formal model to check cost and time that would be required: Cacho and Pheloung, 2007; or IPMDAT), but which have still not spread widely, or which are useful or valuable to people and therefore cannot be eradicated or controlled biologically, should be contained within delimited areas if feasible (Checklist action 2.2f, p.12).

5. Long-term management of an established pest population, including exclusion from defined areas ('site-led' control, including 'mainland islands'), should normally be considered the last resort for managing the invasive species, after eradication, containment and biocontrol have all been deemed not feasible with current or achievable resources (Checklist actions C2.2g and C2.2h, p. 12). In this case, define the management goal more precisely. Why do you want to manage the species (i.e. what damage is it causing and where)? Do you need to manage only in certain areas? Once these questions have been answered you can (1) choose the best techniques and (2) decide where to use them. Chemical, physical or genetic methods can be used. Using these options implies permanent costs, and the level of control that can be achieved will depend on the annual budget available.

6. Mitigation. Where control of the population of an invasive is too expensive or difficult by any of the above methods, consider mitigation of its impacts by methods other than by managing the invasive species itself (see Checklist action C2.2i, p. 12). 
The above hierarchy of management goals, when to use them and the techniques that can be used to achieve them, can be summarised as follows:

\begin{tabular}{|c|c|c|c|c|}
\hline Priority & Management goal & Techniques used & Cost characteristics & Most useful for \\
\hline 1 & Prevention & $\begin{array}{l}\text { Inspections, trapping, baiting etc. } \\
\text { at points of entry }\end{array}$ & $\begin{array}{l}\text { Cheapest method for } \\
\text { multiple species }\end{array}$ & Species not yet present \\
\hline 2 & Eradication & $\begin{array}{l}\text { Physical (shooting, trapping, } \\
\text { uprooting...), chemical } \\
\text { (pesticides), genetic (sterile male, } \\
\text { transgenes etc.) }\end{array}$ & $\begin{array}{l}\text { High initial cost but } \\
\text { minimal after eradication } \\
\text { achieved }\end{array}$ & $\begin{array}{l}\text { Species present in small } \\
\text { areas, including new } \\
\text { arrivals. }\end{array}$ \\
\hline 3 & $\begin{array}{l}\text { Permanent reduction } \\
\text { in population size, } \\
\text { vigour or impact }\end{array}$ & $\begin{array}{l}\text { Biological control, genetic pest } \\
\text { management }\end{array}$ & $\begin{array}{l}\text { Cost high for new agents, } \\
\text { low for well-known ones, } \\
\text { and minimal after effective } \\
\text { agent established }\end{array}$ & $\begin{array}{l}\text { Widespread, damaging, } \\
\text { non-useful species }\end{array}$ \\
\hline 4 & Containment & $\begin{array}{l}\text { Physical, chemical or genetic } \\
\text { techniques }\end{array}$ & Permanent costs & $\begin{array}{l}\text { Useful but damaging } \\
\text { species; new arrivals }\end{array}$ \\
\hline 5 & $\begin{array}{l}\text { Long-term population } \\
\text { management, 'site- } \\
\text { led' control, exclusion }\end{array}$ & $\begin{array}{l}\text { Physical, chemical or genetic } \\
\text { techniques; mainland island } \\
\text { techniques }\end{array}$ & Permanent costs & $\begin{array}{l}\text { Widespread, damaging } \\
\text { species for which goals } \\
1-4 \text { not feasible }\end{array}$ \\
\hline 6 & Mitigation & $\begin{array}{l}\text { Direct protection of the value } \\
\text { (e.g. protection of nests or } \\
\text { saplings etc.) }\end{array}$ & Permanent costs & $\begin{array}{l}\text { Species impossible to } \\
\text { control (goals } 1-5 \text { not } \\
\text { feasible) }\end{array}$ \\
\hline
\end{tabular}

Give more attention to Goals 1-3: Prevention, Eradication, Biocontrol

The management goal appropriate for each situation will depend on the individual circumstances. However, it is common for practitioners to undertake long-term control programmes (Goal 5: long-term population management or site-led control), even though these are usually not the best way to use a limited invasive species budget. Invasives management in general needs to shift emphasis away from long-term control and towards Prevention, Eradication and Biological control, which together can be much more efficient and allow more problems to be dealt with for a given budget. These three options are neglected in part because eradication and biocontrol may require a high initial investment or specialist expertise, and because people feel that prevention and eradication of species that are still only present in limited areas does not seem to be 'taking action against the big problems'. But try to bear in mind always that Goals 5 (long-term control) and 6 (mitigation of impacts) are the last resort, and are often the least efficient ways to manage invasives.

\section{Beware of attempting to control an invasive species by using it}

Use of an invasive species may provide economic or other benefits to a few people, so it can create disagreement, and slow or even stop control efforts by creating a valuable resource (the invasive species) that those people wish to keep or even spread. In general, it is inadvisable to base a control programme on income-generation for one sector of the community. Where most stakeholders feel that an invasive should be eradicated but a few see benefits of using the species long-term, involving all legitimate stakeholders in management decisions can help to demonstrate majority support for the eradication (see 'Difficult customers' pp. 16-17). In rare cases there may be no real alternative to control by using - for example harvesting tasty invasive lionfish on Caribbean reefs can help to manage a species that is not susceptible to conventional management techniques. See the table on the next page for guidance on how to decide whether or not to recommend an invasive species to be used commercially. NB the column 'Don't use!' over-rides the column 'Favours use' - any tick in 'Don't use!' means don't use that species at all. 
When and when not to recommend an invasive species for commercial use.

Factor

Species not present in our islands

Species eradication likely to be feasible

Species can be cultivated or bred economically in our islands

Harvesting is likely to encourage beneficiaries to modify habitat to allow the species to spread

Species prone to parasites or pathogens which are invasive or possess wide host range

Commercialisation likely to attract users from outside our islands

Species easily smuggled

Species exclusively harvested from the wild

Harvesting is likely to reduce the population size or range of the species

Adapted from St Lucia National Invasive Species Strategy 2012-2021. <www.ciasnet.org/wp-content/uploads/2013/05/NISS-SLU-finalreformat-v6.pdf>

\section{Making hard decisions: attitude, positive thinking}

Don't starve your priority project of resources, especially if it's an eradication. Allocate to it all it needs (and a bit more), to maximise your chances of success, and then if you have money left in your budget, move on to Priority number 2. Don't jeopardise the success of Priority 1 by trying to fund more projects, and end up failing on all of them. Far better to do one successfully, then move on to the next one.

Don't be paralysed by lack of information. Do something, learn by your mistakes and adapt. If you find that 'no one has ever done this before' (management technique) or you can't find any information on how to manage species $\mathrm{X}$, then consider doing trials (and monitoring and sharing the results). Every successful first management or eradication started with someone who had noone to copy.

But, don't be pressured into trying to 'do something' about a big problem, when you have only little money. Resist the pressure, leave it alone, and tackle something where you can make a difference (bear in mind the message in the green box above). 


\section{How to: translate the plan into action}

- A plan should not be 'what we'd like to do' - that kind of wish-list is pointless, because we all already know that we'd like to do everything!

- A good plan sets out 'what we are going to do in the next $X$ years'.

If your team has followed these Guidelines when writing the plan, then the plan will be realistic and achievable with the resources at your disposal or readily obtained. Therefore, translating it into action on the ground should not be too difficult. That is the whole point of a good plan - you should be able to complete the actions in it. So, in order to translate your good plan into action, all you need to do is get on with it!

The Actions should already be clearly identified in your Action Plan. Each Action becomes one or more projects. Implementing projects involves a different level of planning, 'operational planning', which is part of the 'Project Cycle'.

\section{The 'Project Cycle’}

1. The cycle begins with Project Selection.

This includes assessing the risk of possible species, pathways and sites (see pp. 29-31),

6. But don't forget Sustaining the Project. Monitor results until the desired outcome has been reached, disseminate the results to the island invasives network, keep monitoring to detect any resurgence or unwanted outcomes, and adapt your management in response to the findings.

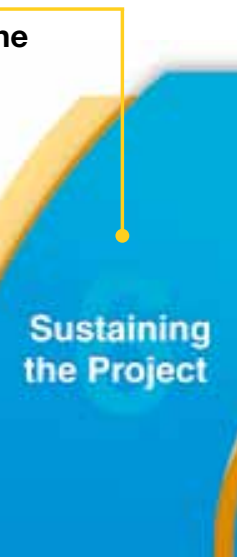

5. At last you can begin Implementation of the management

project.

\section{(1)}

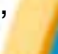

selecting priority targets, and selecting a management goal and method for each one. Much of this will already have been done when you wrote your overall Action Plan. 
Throughout this cycle, be inclusive. As with planning in general, the decision-making processes in project planning should involve as many stakeholders as possible. For biosecurity or eradication projects, the whole population of an island may need to be involved. Even when dealing with an invasion within a reserve or protected area (where a management agency may be entirely responsible), remember that invasive species don't see boundaries, so the project may need to embrace surrounding areas, to minimise spread back into the conservation area. Where possible, take a landscape-scale approach to planning, and involve the surrounding landowners.

\section{After selecting your project}

Step 2. The Feasibility Study should be carried out by an expert in the field. Wherever possible include a cost-benefit analysis, which not only assists decision making, but can also be used to justify applications for funds by showing both the cost of no action and the financial benefit of funding the management proposed. The cost-benefit analysis should also consider whether the invasive species benefits some stakeholders. Techniques for cost-benefit analyses are described in Emerton and Howard, (2008), and examples of this approach on islands include Buncle, et al., (2013) and Daigneault and Brown, (2013).

Step 3. In the Project Design step, the project should be budgeted in detail, to confirm that available financial and other resources allow the activities to be sustained until the desired result is achieved. This is crucial - many management actions are undertaken with insufficient funds or time, which results in failure to achieve effective management, or later resurgence of the invader: i.e. the money was wasted. Conducting a small-scale pilot study at one or a few sites and recording detail of labour time and costs can be used to budget for a bigger project. Include the time and cost involved in gathering supplies and equipment, mobilising teams and gear, doing the field work, tidying up, site restoration, and analysing and writing up results. Estimating the value of in-kind contributions is useful for leveraging actual funds (e.g. university $X$ is giving us $\$ 10,000$ worth of staff time to identify samples, please give us the $\$ 1,000$ in staff salaries we need to collect them).

Steps 4 and 5. As explained in the introduction, these Guidelines do not go into great detail about project planning or implementation, because there are many resources available already to help with that, dealing with everything from prevention to restoration, and from Ants to Zebra Mussels. More detail on best practices for various aspects of management can be found in Resources (p. 40), but don't stop there - use your invasives networks, such as aliens-I, to ask questions and find expertise. For eradication, advisory groups include Island Conservation (www.islandconservation.org) and the New Zealand Department of Conservation's Island Eradication Advisory Group (www.doc.govt.nz/footer-links/ contact-us/).

Step 6. Sustaining the project. If you have followed these Guidelines, the management action you have chosen will have an expected result that is measurable. Make sure that you measure it, i.e. efficiently collect and analyse monitoring data. The monitoring should do four things: (i) measure the success of the management action, e.g. in preventing establishment, or reducing the population of the target invasive, (ii) measure the recovery of the damaged ecosystem or the threatened species, or other damaged value, (iii) allow you to detect any unwanted effects of the management, such as death of non-target species, or invasion by another invasive species, (iv) trigger further action according to the results measured. Point (iv) is important - monitoring without responses is just watching. Include measures to deal with unwanted effects if they occur, and incorporate plans for further invasives management as well as restoration of the ecosystem or particular rare species which might need additional help. This results in an ecosystem approach, with adaptive management to enable you to deal with unexpected results. Monitoring also produces useful information for planning future projects, and so feeds back to Step 1 in the Project Cycle (which is why it's called a cycle). 


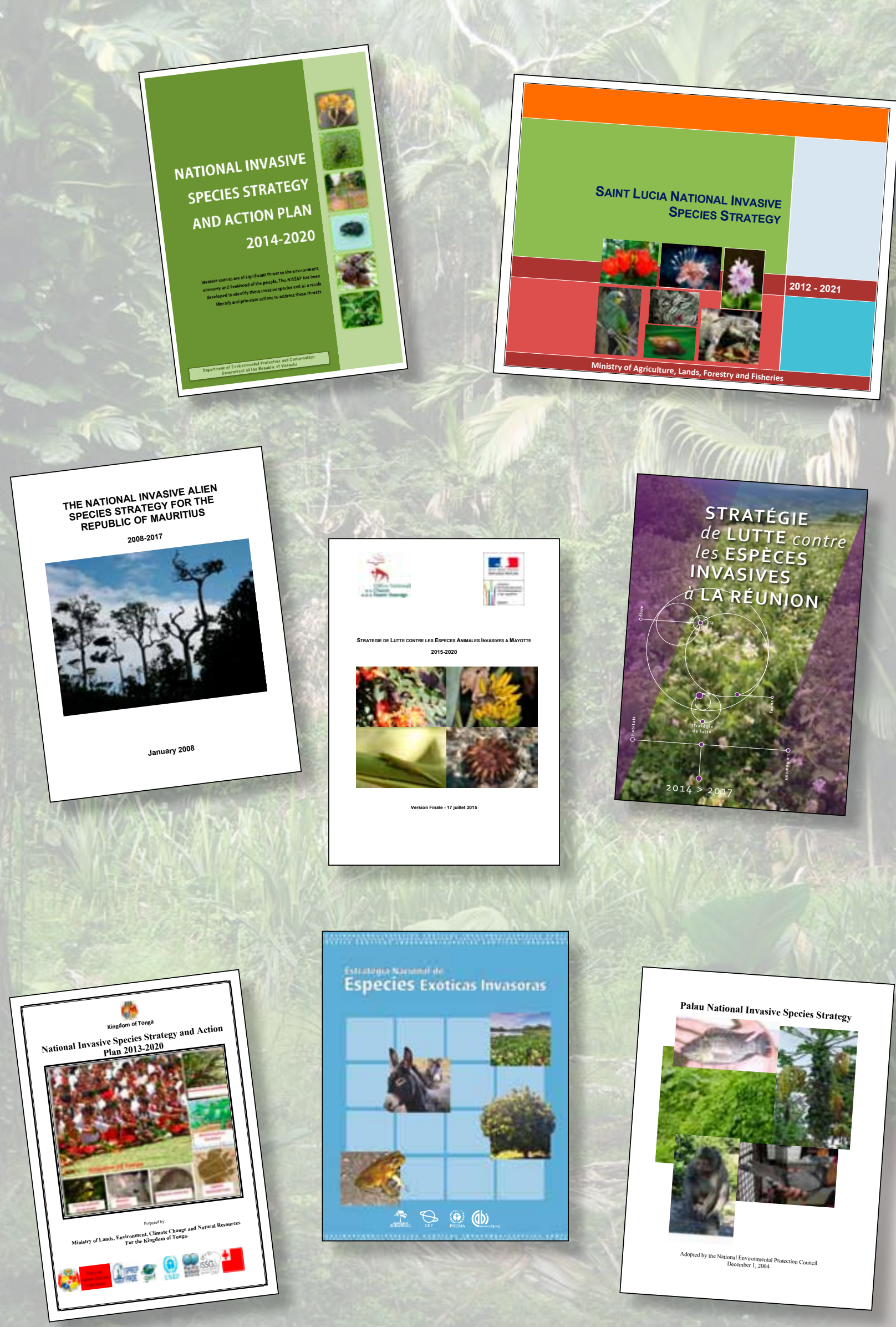




\section{Resources}

\section{Global instruments covering invasive species issues}

Convention on Biological Diversity (CBD or Rio Convention; Article 8h urging contracting parties to manage invasive species) <www. cbd.int/>, and its Aichi Targets for the Conservation of Biodiversity (especially Target 9 Invasive Species understanding, prevention and management) <www.cbd.int/sp/targets/>

International Convention for Control and Management of Ships' Ballast Water and Sediments (BWMC) <www.imo.org/en/About/ Conventions/ListOfConventions/Pages/International-Convention-for-the-Control-and-Management-of-Ships\%27-Ballast-Waterand-Sediments-(BWM).aspx>

International Plant Protection Convention <www.ippc.int/>

United Nations Sustainable Development Goals <www.un.org/sustainabledevelopment/sustainable-development-goals/>

World Organisation for Animal Health (OIE) <www.oie.int/>

\section{Regional strategies and instruments}

European Union regulations and guidance on the prevention and management of invasive alien species <http://ec.europa.eu/ environment/nature/invasivealien/index_en.htm>. Good examples for development of laws and regulations, risk assessments and other studies.

South Atlantic Invasive Species Strategy and Action Plan <http://ww2.rspb.org.uk/Images/SAIS_Strategy_Plan_tcm9-273308.pdf>

\section{National plans}

National Biodiversity Strategies and Action Plans (NBSAPs) prepared by CBD contracting parties are public and available at $<$ https:// www.cbd.int/nbsap/>.

National Development Strategies <www.un.org/en/development/desa/policynotes.html >

National Invasive Species Strategies and Action Plans (NISSAPs). Many can be found here <www.issg.org/publications.htm\#nissap $>$ and elsewhere online.

\section{Resources on multiple themes of these Guidelines}

\section{Global Invasive Species Programme}

Toolkits and Guidelines: <www.issg.org/gisp_guidelines_toolkits.htm>

Training course materials: <www.issg.org/gisp_training_coursematerials.htm>

PILN Battler Resource Base <https://www.sprep.org/piln/resource-base>: 'how-to' guides on many of the themes of these Guidelines, including Awareness Campaigns, Economic Analysis, Marine Invasives, Using Online Databases and many others.

\section{Selected resources related to sections of the Guidelines checklist}

Includes only references mentioned in the text or particularly useful examples. This list is not exhaustive and much more information can be found online or by asking on the invasives e-mail distribution lists listed under A3 below.

\section{A1 Gap analyses}

Boudjelas, S. (2018) A review of national and island plans for the management of invasive species in the Western Indian Ocean region. IUCN.

Doherty, N. and Boudjelas, S. (2010) Invasive Species Management in the Pacific: a review of national plans and current activities. Unpubl. report for the Pacific Invasives Partnership. Auckland: Pacific Invasives Initiative. <www.issg.org/cii/Electronic\%20references/pii/ references/pii_ism_in_the_pacific_a_review_of_national_plans_and_current_activities.pdf $>$.

Key, J. (2017) Tackling Invasive Non-Native Species in the UK Overseas Territories - Gap Analysis of Biosecurity Capacity. GB Nonnative Species Secretariat, York. <https://secure.fera.defra.gov.uk/nonnativespecies/downloadDocument.cfm?id=1566>

SPREP (2009) Guidelines for Invasive Species Management in the Pacific. SPREP, Apia.

A2 Gaining support; awareness messages including cost-benefit analysis

Buncle, A., Daigneault, A., Holland, P., Fink, A., Hook, S. and Manley, M. (2013) Cost-benefit Analysis for Natural Resource Management in the Pacific. A Guide. SPREP, Apia. <https://pdfs.semanticscholar.org/5a08/3078ee7f17cebbb9b6dd6b27fe9b7d782bb4.pdf>

Daigneault and Brown, P. (2013) Invasive species management in the Pacific using survey data and benefit-cost analysis. <https:// ageconsearch.umn.edu/bitstream/152140/2/CP\%20Brown.pdf>

Emerton, L. and Howard, G. (2008) A toolkit for the economic analysis of invasive species. Global Invasive Species Programme, 110pp. $<$ https://portals.iucn.org/library/node/9248> 
Madden, F. and McQuinn, B. (2014) 'Conservation's blind spot: the case for conflict transformation in wildlife conservation.' Biological Conservation 178: 97-106. <https://doi.org/10.1016/j.biocon.2014.07.015>

Novoa, A. et al. (2018) 'A framework for engaging stakeholders on the management of alien species.' Journal of Environmental Management 205: 286-297. <https://doi.org/10.1016/j.jenvman.2017.09.059>

\section{A3 Invasives networks and email lists}

Caribbean Invasive Alien Species Network (CIASNET) <www.ciasnet.org/>. E-mail list: carib_ias_threat Island Conservation Network <http://listserv.bgci.org/scripts/wa.exe?A0=islands-I>. E-mail list: islands-I IUCN Invasive Species Specialist Group (ISSG). <www.issg.org/>. E-mail list: aliens-I

Pacific Invasives Initiative (PII) <www.pacificinvasivesinitiative.org/>. E-mail list pii@auckland.ac.nz

Pacific Invasives Learning Network (PILN) <www.sprep.org/piln $>$.

Pacific Invasives Partnership (PIP) <www.sprep.org/Pacific-Invasives-Partnership/invasive-partnerships >

Pestnet <www.pestnet.org/PestNet.aspx>. E-mail list: pestnet.

Western Indian Ocean Network on Invasive Species (WIONIS). <www.agriculture-biodiversite-oi.org/en/WIONIS/WIONIS-the-Network wio-ias>. E-mail list: wio-ias.

\section{A3 Regional agencies and initiatives}

Caribbean Community (CARICOM) <http://caricom.org/about-caricom/who-we-are >

Regional Activity Centre for the Protocol Concerning Specially Protected Areas and Wildlife for the Wider Caribbean Region (CARSPAW-RAC) <www.car-spaw-rac.org/>

Indian Ocean Commission (IOC) <www.commissionoceanindien.org/>

Secretariat of the Pacific Regional Environment Programme (SPREP) <www.sprep.org $>$

IUCN French Committee Initiative sur les Espèces Exotiques Envahissantes en Outre-mer. <www.especes-envahissantes-outremer.fr/> The Pacific Community (SPC) <www.spc.int>

\section{A3 Online information resources on invasive species}

CABI Invasive Species Compendium <www.cabi.org/isc >: extensive information on pests, weeds and diseases, taxonomy, invasiveness, distribution, management.

DAISIE <www.europe-aliens.org/aboutDAISIE.do $>$ : information on invasives in Europe, including many islands.

Database of Island Invasive Species Eradications (DIISE) <http://diise.islandconservation.org/>

FishBase $<$ www.fishbase.org/ $>$ : can search by country for introduced or invasive fish.

Global Biodiversity Information Facility (GBIF) <www.gbif.org/>: records and taxonomy.

Global Invasive Species Database (GISD) <www.iucngisd.org/gisd/>: detailed information on selected invasives.

Global Register of Introduced and Invasive Species (GRIIS) <www.griis.org/>: species lists by country.

HEAR <www.hear.org >: many invasive topics, including the Global Compendium of Weeds $<$ www.hear.org/gcw/ $>(>20,000$ taxa with literature citations).

The IABIN Invasives Information Network $(I 3 N)<$ www.institutohorus.org.br/iabin/i3n/> information on invasives in the Americas, including many islands.

Island Biodiversity and Invasive Species Database (IBIS) <http://ibis.fos.auckland.ac.nz/>: which invasives threaten which endemics?

Pacific Islands Ecosystems at Risk (PIER) <www.hear.org/pier/>: lists and information on invasive plants on islands in the Pacific and elsewhere. Pre-done weed risk assessments are at $<$ www.hear.org/pier/wralist.htm $>$.

Pacific Pest List Database $<w w w . s p c . i n t / p l d />$ : pest records in Pacific islands.

PI@ntNet <https://plantnet.org/>: get your plant photos identified.

Threatened Island Biodiversity database (TIB) <http://tib.islandconservation.org/>: information useful for prioritising islands for management.

US National Invasive Species Information Centre <www.invasivespeciesinfo.gov/resources/databases.shtml>: information on many common invasives.

WikWIO <www.wikwio.org/idao/>: weed identification tool.

Weeds of National Significance (WONS: Australian) <www.weeds.org.au/WONS/>: accounts of some of the worst invasive plants plus management techniques.

World Register of Introduced Marine Species (WRIMS) <www.marinespecies.org/introduced/>

\section{A4 Legislation, policy and regulation}

Models for policies and legislation for invasives management are available from the IUCN Law Centre (<www.iucn.org/about/work/ programmes/environmental_law>), which can advise on different types of legislation for different situations including islands and island nations.

Shine, C. (2008) A Toolkit for Developing Legal and Institutional Frameworks for Invasive Alien Species. Global Invasive Species Programme. <www.issg.org/gisp_guidelines_toolkits.htm>

\section{B2 Prioritisation and risk analysis}

Dawson, J., Oppel, S., Cuthbert, R.J., Holmes, N., Bird, J.P., Butchart, S.H.M., Spatz, D.R. and Tershy, B. (2014) 'Prioritizing islands for the eradication of invasive vertebrates in the United Kingdom overseas territories.' Conservation Biology 29: 143-153.

Hulme, P.E., Bacher, S., Kenis, M., Klotz, S., Kühn, I., Minchin, D., Nentwig, W., Olenin, S., Panov, V., Pergl, J., Pysek, P., Roques, A., Sol, D., Solarz, W. and Vilà, M. (2008) 'Grasping at the routes of biological invasions: a framework for integrating pathways into policy.' Journal of Applied Ecology 45: 403-414. 
IUCN (2017b) Guidance for interpretation of CBD categories on introduction pathways. Technical note prepared by IUCN for the European Commission. <https://circabc.europa.eu/sd/a/738e82a8-f0a6-47c6-8f3b-aeddb535b83b/TSSR-2016-010\%20CBD\%20 categories\%20on\%20pathways\%20Final.pdf>

McGeoch, M.A., Genovesi. P., Bellingham, P.J., Costello, M.J., McGrannachan, C. and Sheppard, A. (2016) 'Prioritizing species, pathways, and sites to achieve conservation targets for biological invasion.' Biological Invasions 18: 299-314.

Pest and Weed Risk Assessment, widely used systems and examples:

Australia WRA <www.agriculture.gov.au/biosecurity/risk-analysis/weeds/system>

Hawai'i WRA < www.botany.hawaii.edu/faculty/daehler/wra/s

IPPC training on PRA <https://www.ippc.int/en/core-activities/capacity-development/training-material-pest-risk-analysis-basedippc-standards/>

Many other examples may be found by searching the internet.

\section{C1 and C2 Best practice prevention and management}

\section{General best practice}

IUCN (2000) Guidelines for the Prevention of Biodiversity Loss Caused by Alien Invasive Species. IUCN, Gland. <https://portals.iucn. org/library/node/12413>

IUCN (2017a) Guidance Note for Pest Management Planning. Environmental \& Social Management System, IUCN, Gland. <www.iucn. org/sites/dev/files/iucn_esms_pest_management_guidance_note.pdf>

Rocamora, G. and Henriette, E. (2015) Invasive Alien Species in Seychelles. Why and how to eliminate them. Biotope, Mèze. (Good practice guide, useful for islands anywhere.)

Wittenberg, R. and Cock, M.J.W. (eds.) (2001) Invasive Alien Species: A Toolkit for Best Prevention and Management Practices. Global Invasive Species Programme. <www.issg.org/gisp_guidelines_toolkits.htm>

\section{Biosecurity}

Bern Convention codes of conduct for managing introduction pathways. <https://www.coe.int/en/web/bern-convention/on-invasivealien-species\#\{“12475592":[1]\}>

Invasive Species Council (2017) Environmental Biosecurity: Best Practice. <https://invasives.org.au/publications/biosecurity-bestpractice/>

\section{Biological control}

CRC Weed Management (2008) Best Practice Guides:

1 Impact evaluation of weed biological control agents. <www.utas.edu.au/__data/assets/pdf_file/0011/636149/Best-PracticeGuide-1-Impact-evaluation-of-weed-biological-control-agents.pdf>

2 Release and establishment of weed biological control agents. <www.utas.edu.au/__data/assets/pdf_file/0004/373567/BestPractice-Guide-2-Release-and-establishment-of-weed-biological-control-agents.pdf $>$

Day, M.D. and Winston, R.L. (2016) 'Biological control of weeds in the 22 Pacific island countries and territories: current status and future prospects.' Neobiota 30: 167-192. <https://doi.org/10.3897/neobiota.30.7113>

iBiocontrol. Biological Control of Weeds: a world catalogue of agents and their target weeds. <www.ibiocontrol.org/catalog/>

Eradication tools and principles

Cacho, O. and Pheloung, P. (2007) WeedSearch weed eradication feasibility analysis. University of New England, Armidale. Manual and software available at: <https://www.une.edu.au/staff-profiles/business/ocacho > Tool for assessing cost and eradication feasibility.

IPMDAT Invasive Plant Management Decision Analysis Tool. <www.ipmdat.org/home.html $>$ Tool for assessing cost and eradication feasibility.

Parkes, J.P. and Panetta, F.D. (2009) 'Eradication of invasive species: progress and emerging issues in the 21st century'. In: Clout, M.N. and Williams, P.A. (eds) Invasive Species Management. A handbook of principles and techniques, pp. 47-60. Oxford University Press, Oxford. Eradication criteria.

\section{Genetic techniques}

Harvey-Samuel, T., Ant, T. and Alphey, L. (2017) 'Towards the genetic control of invasive species.' Biological Invasions 19: 1683-1703. Review of potential for use in eradication, population reduction, containment etc. $<$ https://doi.org/10.1007/s10530-017-1384-6>

\section{Managing particular kinds of organism}

Orueta, J. (2003) Manual práctico para el manejo de vertebrados invasores en islas de España y Portugal. <www.interreg-bionatura. com/especies/docs/ManualPracticoVertebradoslslas.pdf>

Thomas, S., Varnham, K. and Havery, S. (2017) Current Recommended Procedures for UK (Bait Station) Rodent Eradication Projects. Version 4.0, Royal Society for the Protection of Birds. <www.nonnativespecies.org/index.cfm?pageid=613>

New Zealand MFAT (2016) Pacific Invasive Ant Toolkit. <www.piat.org.nz/>

Pacific Invasives Initiative (2011) Resource Kit for Rodent and Cat Eradication. <http://rce.pacificinvasivesinitiative.org/>

Pacific Invasives Initiative (2015) Resource Kit for Invasive Plant Management. <http://pacificinvasivesinitiative.org/ipm/ipm. pacificinvasivesinitiative.org/index.html>

\section{Marine invasives}

Globallast programme: <http://archive.iwlearn.net/globallast.imo.org/> Resources on the management of ships' ballast water and sediments.

Hilliard, R. (2005). Best Practice for the Management of Introduced Marine Pests - A Review. Global Invasive Species Programme. $<$ www.issg.org/gisp_guidelines_toolkits.htm>

Jackson, L. (2008) Guidelines for the Prevention and Management of Marine Biofouling and Invasive Species. Global Invasive Species Programme. <www.issg.org/gisp_guidelines_toolkits.htm>

\section{C3 Restoration}

Society for Ecological Restoration <www.ser.org >: much information on a variety of approaches. 



\section{IUCN}

INTERNATIONAL UNION

FOR CONSERVATION OF NATURE

WORLD HEADQUARTERS

Rue Mauverney 28

1196 Gland, Switzerland

Tel: +41 229990000

Fax: +41 229990002

www.iucn.org 